\title{
Design method of a compact static nonimaging concentrator for portable photovoltaics using parameterisation and numerical optimisation.
}

FREIER RAINE, D., RAMIREZ-INIGUEZ, R., JAFRY, T., MUHAMMAD-

SUKKI, F. and GAMIO, C. 


\title{
Design method of a compact static nonimaging concentrator for portable photovoltaics using parameterisation and numerical optimisation
}

\author{
Daria Freier Raine ${ }^{a *}$, Roberto Ramirez-Iniguez ${ }^{\text {a }}$, Tahseen Jafry ${ }^{\text {a }}$, Firdaus Muhammad-Sukki ${ }^{\text {b }}$, Carlos Gamio a \\ a School of Engineering \& Built Environment, Glasgow Caledonian University, 70 Cowcaddens Road, \\ Glasgow, G4 0BA, Scotland, UK, \\ ${ }^{\mathrm{b}}$ School of Engineering, Robert Gordon University, Garthdee Road, Aberdeen, AB10 7GJ, Scotland, UK \\ * Email: daria.freier@gcu.ac.uk,daria_freier@outlook.de
}

\begin{abstract}
Portable solar chargers are one of the technologies that can help to achieve universal access to electricity by 2030 . However, the large number of solar photovoltaic devices required and their short life-span make achieving this goal a resource and energy intensive process. To reduce the embodied energy, the embodied carbon and the human and eco-toxicity potential of portable solar chargers, solar photovoltaic concentrators can be used. This paper proposes a new nonimaging solar photovoltaic concentrator design which has material efficiency, portability and off-grid use as its main feature. The main contribution of this paper is the design method of the new 3D nonimaging concentrator containing the parametric equation of the concentrator surfaces and the numeric optimisation of the design parameters. The developed optimisation program is based on genetic algorithms which parameters were determined experimentally in this paper. The concentrator design achieved with this method is $43 \%$ less material intensive than the most compact nonimaging solar concentrator available in literature. This design approach can be used to find concentrator designs with specific volumes, heights, concentration ratios, acceptance angles and optical efficiency. It is therefore a step towards more material efficient and more sustainable nonimaging concentrators and more sustainable portable solar photovoltaic systems.
\end{abstract}

Key words: CPV; portable solar; nonimaging concentrator; numerical optimization; sustainable solar photovoltaics

\section{Acronyms}

3D CCPC 3D crossed compound parabolic concentrator

BICPV Building integrated concentrated photovoltaic

CRSH Circular rotational square hyperboloid 


\begin{tabular}{ll}
\hline GOCRSH & Genetically optimised circular rotational square hyperboloid \\
RACPC & Rotationally asymmetrical compound parabolic concentrator \\
RADTIRC & Rotationally asymmetrical dielectric totally internally reflective concentrator \\
SEH & Square elliptical hyperboloid \\
\hline
\end{tabular}

\section{Nomenclature}

\begin{tabular}{|c|c|c|}
\hline Symbol & Description & Unit \\
\hline$a$ & Exit aperture width of the GOCRSH 2D cross-section & $\mathrm{m}$ \\
\hline A entrance & Entrance aperture area & $\mathrm{m}^{2}$ \\
\hline$A_{\text {exit }}$ & Exit aperture area & $\mathrm{m}^{2}$ \\
\hline$C_{g}$ & Geometric concentration ratio & \\
\hline$c_{m}$ & Fitness scaling parameter & \\
\hline$C_{o p t}$ & Optical concentration ratio & \\
\hline$C_{o p t \pm 40^{\circ}}$ & Averaged optical concentration ratio within the angles of incidence of $\pm 40^{\circ}$ & \\
\hline$d$ & Exit aperture width & $\mathrm{m}$ \\
\hline$d_{f 1}$ & Dimensionality factor 1 & $\mathrm{~m}^{-1}$ \\
\hline$d_{f 2}$ & Dimensionality factor 2 & $\mathrm{~m}^{-3}$ \\
\hline$f_{\text {ave }}$ & Averaged fitness of a population & \\
\hline$f_{i}$ & Fitness of an individual & \\
\hline$f_{i}^{\text {scaled }}$ & Scaled fitness of an individual & \\
\hline$f_{s}$ & Parametric equation of the GOCRSH entrance surface aperture & \\
\hline$f_{s_{-} i}$ & Selection probability of an individual & \\
\hline$h_{m}$ & Maximum concentrator height & $\mathrm{m}$ \\
\hline$h_{P}$ & GOCRSH side profile height & $\mathrm{m}$ \\
\hline$k$ & Order of root & \\
\hline$L$ & Number of bits in a chromosome & \\
\hline$N$ & Number of individuals in a population & \\
\hline$P_{c}$ & Crossover probability & \\
\hline$P_{m}$ & Mutation probability & \\
\hline$R$ & Entrance aperture radius & $\mathrm{m}$ \\
\hline$R_{c}$ & Circle radius of the GOCRSH entrance aperture arc & $\mathrm{m}$ \\
\hline$T_{c}$ & Randomly generated number in the crossover operator & \\
\hline$T_{m}$ & Randomly generated number in the mutation operator & \\
\hline$x_{c}$ & Circle centre $\mathrm{x}$-coordinate of the arc & \\
\hline$y_{c}$ & Circle centre y-coordinate of the arc & \\
\hline$\beta_{\text {entrance }}$ & Radiant flux at the entrance aperture & W \\
\hline
\end{tabular}




\begin{tabular}{ll}
\hline$\eta_{o p t}$ & Optical efficiency \\
$\eta_{o p t \pm 40^{\circ}}$ & Averaged optical efficiency within the angles of incidence of $\pm 40^{\circ}$ \\
$\theta_{t h}$ & Rotation angle
\end{tabular}

\section{Introduction}

Off-grid solar chargers are expected to play a major role in enabling a sustainable development. Whilst being arguably more sustainable than local diesel generators, solar chargers are still potentially harmful to the environment and this increases with the number of devices manufactured, sold and disposed of [1]. Silicon photovoltaic (PV) modules are mainly used for portable solar chargers, and their production is very energy intensive leading to increased greenhouse gas (GHG) [2] emissions and involves the use of toxic substances which can harm workers and the environment $[3,4]$. It has been shown that the embodied energy and embodied carbon of the PV module as well as its human and eco-toxicity can be reduced by substituting part of the photovoltaic (PV) material with solar PV concentrators [5]. By focusing light from a large area onto a small area a solar PV concentrator increases the power output of the photovoltaic (PV) cell, hence less photovoltaic material is required [6]. The factor by which the flux density on the PV cell is increased is referred to as concentration ratio. Further terms used in this paper for the description and characterisation of solar concentrators are defined below.

Geometric concentration ratio $\left(C_{g}\right)$ : The geometric concentration ratio is the ratio of the entrance aperture area ( $\left.A_{\text {entrance }}\right)$ to the exit aperture area $\left(A_{\text {exit }}\right)$ as defined in Equation (1) [7].

$$
C_{g}=\frac{A_{\text {entrance }}}{A_{\text {exit }}}
$$

Optical efficiency $\left(\eta_{o p t}\right)$ : The value is usually determined through raytracing where the number of ray intersections with a surface is taken as radiant flux. Optical efficiency is the ratio of radiant flux at the exit aperture $\left(\beta_{\text {exit }}\right)$ to the radiant flux at the entrance aperture ( $\left.\beta_{\text {entrance}}\right)$ (Equation (2)) [7], it is therefore dependant on the angle of incidence of the ray bundle.

$$
\eta_{\text {opt }}=\frac{\beta_{\text {exit }}}{\beta_{\text {entrance }}}
$$

Optical concentration ratio $\left(C_{\text {opt }}\right)$ : The optical concentration ratio is defined as a product of the $\eta_{o p t}$ and the $C_{g}$ (Equation (3)). 


$$
C_{o p t}=C_{g} \times \eta_{o p t}
$$

Acceptance angle: the acceptance angle (or half-acceptance angles) of a concentrator is defined as the angular range within which the optical concentration ratio remains in the range of $90 \%$ of the maximum optical concentration ratio. For concentrators with narrow acceptance angle tracking systems are required to capture the sun rays [8].

Solar PV concentrators have already been utilised in stand-alone and building integrated PV systems, however, there is limited research available on solar concentrators for portable solar systems. The two main portable concentrated solar concepts known are a Fresnel lens based approach by Lewis Fraas et al. $[9,10]$ and an approach based on spectrum splitting by Barnett et al. [11]. Whilst the first is not suitable due to the required tracking and cooling the latter has the complexity of manufacturing and its high cost [12] as the main obstacles for use in rural areas in developing countries [1].

For portable solar systems a solar concentrator needs to fulfil different requirements such as similar acceptance angle at all vertical planes for easy use, a concentration ratio below 10x to not need active cooling and a sufficiently large acceptance angle to enable multiple hours of light collection without tracking. Furthermore, a concentrating system not requiring tracking or cooling is more reliable and has no additional operation and maintenance costs [1].

From a review of existing concentrators published in [1] it was concluded that the most suitable concentrator type for portable solar systems for developing countries is the static nonimaging concentrator since no minimal focal distance, tracking or cooling is required and compact designs can therefore be achieved. A comparative table of the nonimaging concentrator designs is presented in Table 1 which includes nonimaging concentrators proposed for building integrated PV (Refractive 3D CCPC [13], SEH [13], RADTIRC [6], RACPC [14], Aspheric lens [15]) as well as the circular rotational square hyperboloid (CRSH) [16] proposed for portable solar systems for developing countries. The concentrators are rated based on their optical properties as well as on their volume and overall concentrator height to find the most compact and efficient nonimaging concentrator.

Furthermore, the volume and maximum wall thickness of the concentrator have a strong impact on the manufacturing costs. Since no sufficient studies are available on the costs of the concentrators, it is possible to comment on the cost competitiveness of the above nonimaging 
concentrator designs, based on PMMA injection moulding being identified as most suitable for the mass production of nonimaging concentrators [2] [62]. The lens thickness determines the cooling time of the part, which increases quadratically with the lens thickness [17]. Since the cooling time is the largest part of the injection moulding cycle time, it has a strong impact on the costs per unit [17]. At the current manufacturing requirements, a maximum wall thickness not greater than $12.7 \times 10^{-3} \mathrm{~m}$ is recommended [18], however, the value depends on the experience and expertise of the injection moulding company. Since the cooling period increases quadratically with the lens thickness, it is critical to minimise the overall height of the concentrator to minimise costs [17].

Considering the constraints for the use of nonimaging concentrators in portable solar PV systems mentioned above, the design properties of each concentrator are rated in Table 1 using colour coding where red colour stands for a design property prohibitive for implementation, yellow colour for being acceptable and showing potential for improvement and green colour for being suitable for the application in its current form.

Table 1 Comparison of static nonimaging 3D concentrators for their suitability for portable solar systems

\begin{tabular}{|c|c|c|c|c|c|c|}
\hline $\begin{array}{l}\text { Concentrator } \\
\text { designs }\end{array}$ & $\mathrm{C}_{\mathrm{g}}$ & $\begin{array}{c}\text { Max } \eta_{\text {opt }} \\
(\%)\end{array}$ & $\begin{array}{c}\text { Half-acceptance } \\
\text { angles }\left(^{\circ}\right)\end{array}$ & $\begin{array}{l}\text { Volume } \\
\left(10^{-9} \mathrm{~m}^{3}\right)\end{array}$ & $\begin{array}{l}\text { Height } \\
\left(10^{-3} \mathrm{~m}\right)\end{array}$ & Ref \\
\hline $\begin{array}{l}\text { Refractive 3D } \\
\text { CCPC }\end{array}$ & 3.61 & 73 & \pm 40 & 3968 & 16.16 & [13] \\
\hline $\mathrm{SEH} \mathrm{H} / \mathrm{A}=1$ & 4.00 & 40 & \pm 60 & 4019 & 10.00 & [13] \\
\hline RADTIRC & 4.91 & 95 & $\pm 30 / \pm 40$ & 8230 & 30.00 & {$[6]$} \\
\hline RACPC & 3.67 & 93 & \pm 43 & 8538 & 30.00 & [14] \\
\hline Aspheric lens & 4.00 & 47 & \pm 40 & 3200 & 12.24 & [15] \\
\hline CRSH_A & 4.01 & 98.2 & \pm 28 & 7570 & 21.00 & [16] \\
\hline CRSH_B & 3.60 & 97.5 & \pm 32 & 4272 & 16.80 & [16] \\
\hline CRSH_C & 3.46 & 89.9 & \pm 35 & 4045 & 14.10 & [16] \\
\hline
\end{tabular}

Legend: red: prohibitive for implementation; yellow: acceptable for implementation but showing potential for improvement; green: suitable for implementation in its current form.

The comparative table shows that the existing nonimaging concentrators require adjustments to be used for portable solar systems. Whilst the SEH [13] and the Aspheric lens [15] have a favourable height, their optical efficiency is very low which makes the design less compact and 
less material efficient. The RADTIRC [6] and RACPC [14] have a high geometrical concentration ratio and optical efficiency as well as a wide acceptance angle, however, their large height is prohibitive for cost effective manufacturing. The refractive 3D CCPC by Sellami [96] has a wide acceptance angle and geometrical concentration ratio, its optical efficiency however can be further improved and height further reduced. From the CRSH designs the CRSH_C is the most suitable due to its smallest height and widest acceptance angle, its height, however, can be reduced and acceptance angle further improved [16]. Whilst this design has already shown to be more compact than the nonimaging concentrators for building integration presented in Table 1, its design method does not guarantee maximum compactness. In this paper the CRSH design is further optimised to achieve a more compact design while maintaining the optical concentration ratio within a wide acceptance angle of $\pm 40^{\circ}$.

\section{Numerical optimisation in nonimaging optics}

To effectively find a more compact design, numeric optimisation with simultaneous 3D raytracing analysis is proposed. Whilst optimisation is a key component in imaging optical design [19], optimisation in nonimaging optics has been primarily integrated into the design of LED lenses [19], secondary optical element (SOE) homogenisers [19] and Fresnel concentrators [20]. From the nonimaging concentrator designs discussed in [1], all concentrators besides the Square Elliptical Hyperboloid (SEH) proposed by Sellami [13] were designed following the edge-ray principle. The edge-ray principle, however, does not allow for the optimisation of the concentrator volume, leading to less compact designs. A step away from the edge-ray principle was the design of the SEH concentrator by Sellami [13]. Through manual selection of concentrator parameters involving the generation of 160 designs and their evaluation using 3D raytracing, Sellami was able to control the shape and size of the concentrator design. Numerical optimisation can simplify this procedure by optimising all parameters simultaneously. In 1995 Shatz and Bortz [21] introduced the idea of using global optimisation algorithms for the optimisation of nonimaging concentrators, which yielded an improved performance of the rotational CPC. They concluded that nonimaging optical design problems are multimodal, meaning that multiple local optima exist for a set of objectives and constraints. Hence global algorithms are best suited for finding the optimal (or near optimal) parameters for the GOCRSH design. 


\subsection{Global optimisation algorithms}

Global optimisation algorithms can be categorised into deterministic and probabilistic algorithms. Deterministic optimisation algorithms are used when the relation between the parameters and the desired solution is known and a set of starting parameters can be accurately selected, since the latter influences the explored search space as well as the final result [22,23]. Probabilistic optimisation on the other hand is used when the relation between the input parameters and the desired solution is not clear or too complex, or when the search space is too large to be explored deterministically [24]. In contrast to deterministic methods, worse solutions get accepted in the probabilistic methods, as it increases the search space and prevents mistaking the local optimum for the global optimum [22,25]. Since a change in parameters leads to a different optical concentration ratio, which for the proposed design can only be retrieved from a $3 \mathrm{D}$ raytracing analysis, the relation between the input parameters and the desired solution is not clear. Hence, probabilistic optimisation was selected for the problem at hand.

Probabilistic optimisation algorithms such as genetic algorithms (GAs) have shown the quality of avoiding entrapment in local optima and the ability to continue the search to arrive in an optimum or near-optimum solution [26]. GAs belong to evolutionary algorithms (EA), which are also part of soft computing and artificial intelligence [25]. EA and GAs, are a welldeveloped field of computer science and have been used successfully in many applications, for instance in image processing, medicine, robotics, spacecraft trajectories, stand-alone renewable energy systems [27] and microgrids [24,28]. They have proved particularly useful where the search space is large, noisy, discontinuous or multimodal [29]. For concentrator optimisation, GAs have been employed for the optimisation of nonimaging Fresnel lenses [20,30,31], parabolic troughs [32] and V-toughs [33], yet not for 3D nonimaging static Low Concentration Photovoltaic (LCPV) concentrators.

GAs are based on the evolutionary theory in biological organisms, where the genepool of a population changes over time in favour of the desirable traits for the environment. The population in our case consists of concentrator designs (individuals), which are characterised by their parameters (chromosomes). Like in selective breeding, two individuals are selected to form a mating pair based on their fitness. To create offspring parts of the chromosomes of the selected pair is swapped which is known as crossover. Consequently, the mutation operator is 
applied to increase the search space by introducing new random genes [24]. The individuals of the new generation are analysed, and the selection, crossover and mutation process repeated forming new generations to produce fitter and fitter individuals until a stopping criterion of the algorithm is exceeded. Figure 1shows a simplified flowchart of a GA used in this optimisation [34]. The preliminary results of the concentrator optimisation were published in [35] which show the suitability of the genetic algorithms for this type of optimisation problem.

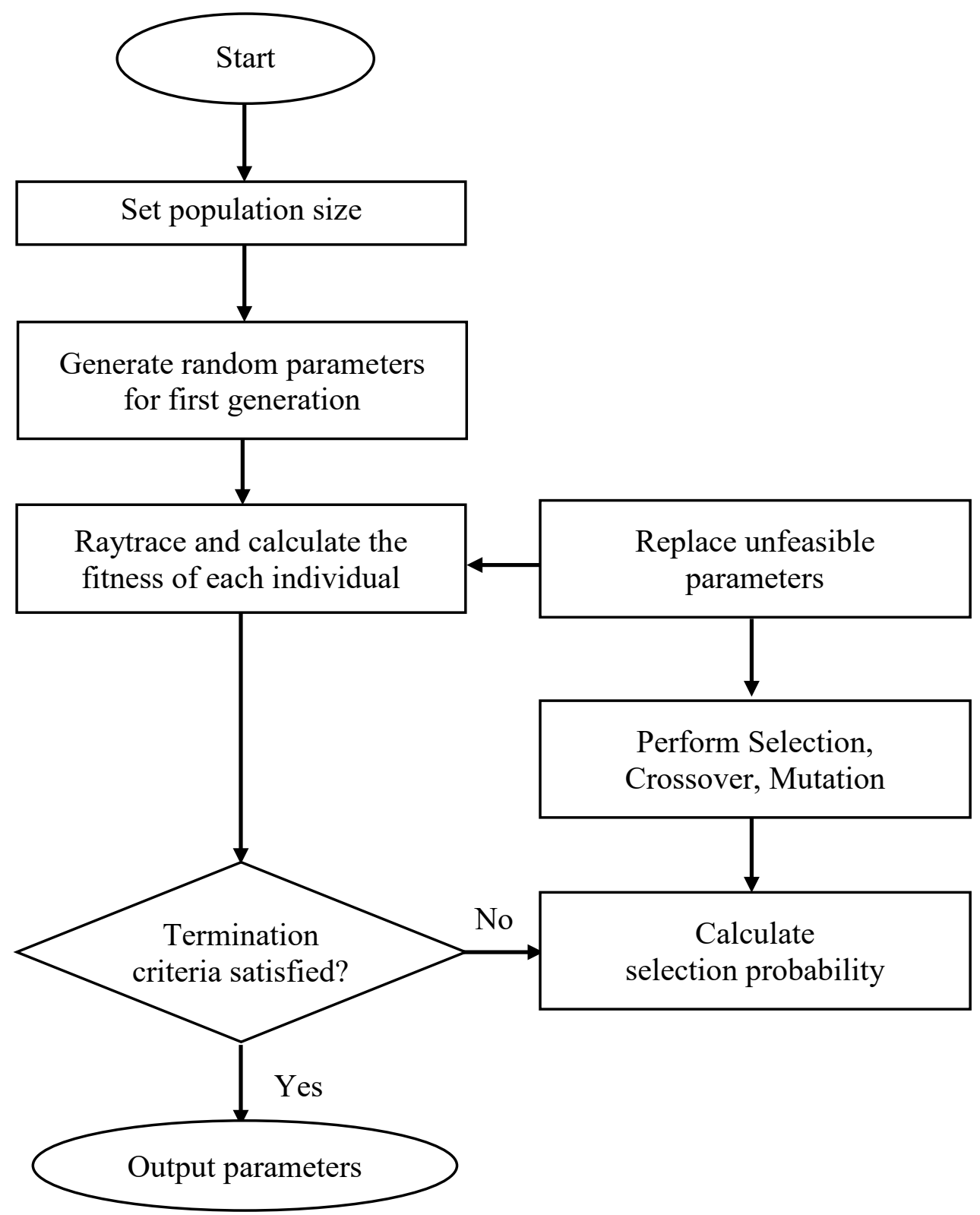

Figure 1. Simplified flow chart of the genetic algorithm GA used in this optimisation 


\section{Parameterisation of the concentrator design}

\subsection{Parameterisation of the entrance aperture}

To be able to numerically optimise the CRSH concentrator, the concentrator surfaces need to be in a parametric form. The initial CRSH design has a rotationally symmetric entrance aperture designed point by point, a hyperbolic side-profile and a $100 \times 10^{-6} \mathrm{~m}^{2}$ square exit aperture [35]. The point by point created entrance surface aperture can be approximated in 2D as an arc with the following parameters: the position of the circle centre point in relation to the origin of the Cartesian coordinate system $\left(x_{c}, y_{c}\right)$ and the circle radius $R_{c}$ (Figure 2). The circle arc between the positive $y$ and $x$ axes gives the profile of the entrance aperture. By modifying $x_{c}, y_{c}$ and $R_{c}$ an effective optimisation of the surface entrance aperture can be achieved.

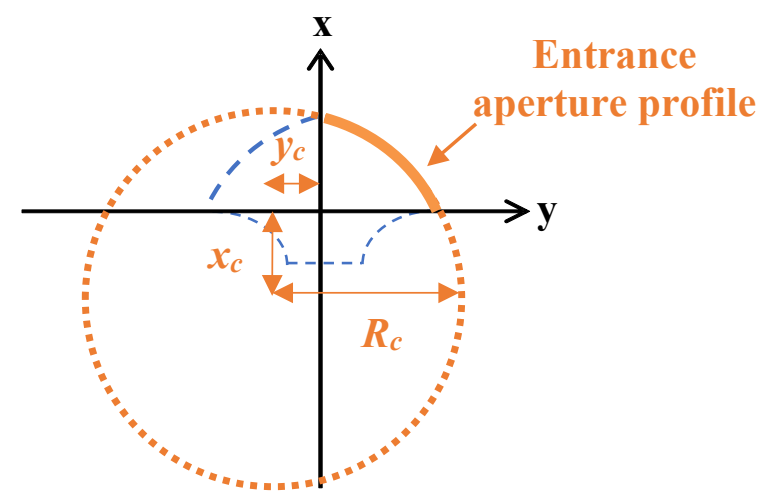

Figure 2. Parameters of the GOCRSH entrance aperture profile, side view

The arc is rotated around the $\mathrm{x}$-axis to create the symmetrically rotational entrance surface aperture (Figure 3). The parametric equation of the entrance aperture is given by Equation (4), which is the adapted equation of a circle, where $r$ represents the distance of the incident ray to the symmetry axis of the design (Equation (5)) as shown in Figure 3.

$$
\begin{gathered}
f_{s}(r)=-\sqrt{{R_{c}{ }^{2}-\left(-r-x_{c}\right)^{2}}^{2}}+y_{c} \\
r(y, z)=\sqrt{y^{2}+z^{2}}
\end{gathered}
$$




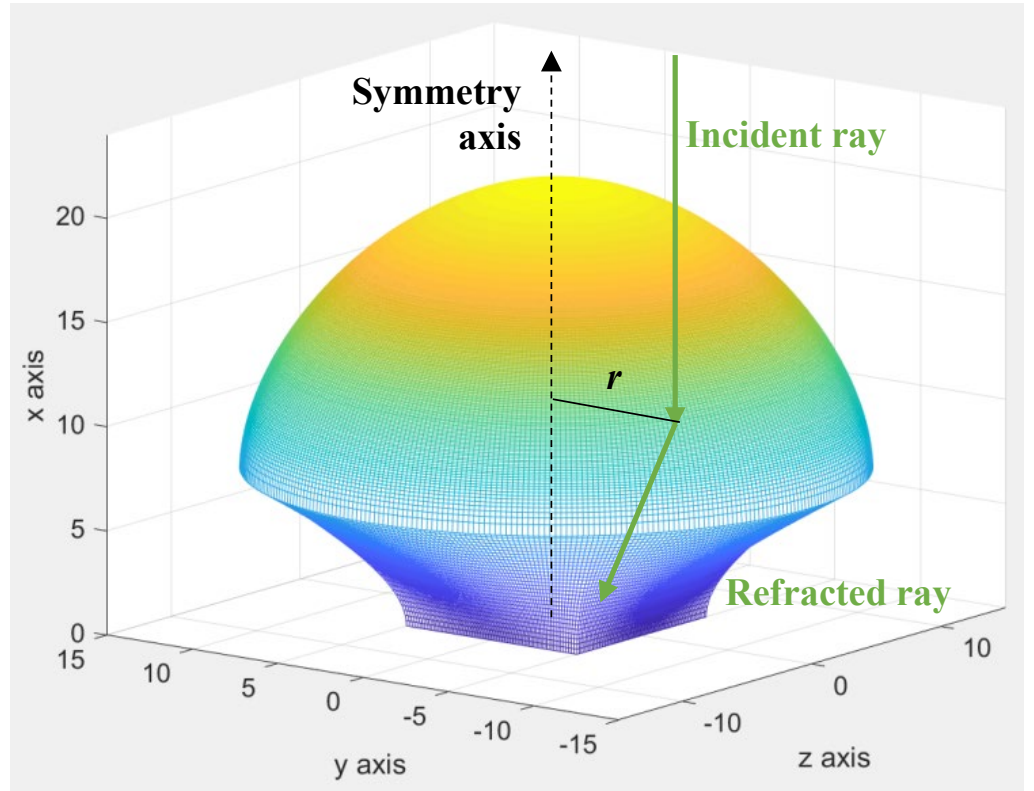

Figure 3. Distance of the incident ray $r$ to the concentrator symmetry axis, 3-D view of the GOCRSH, axis units in $10^{-3} \mathrm{~m}$

\subsection{Parameterisation of the side profile}

The hyperbolic side profile has three parameters: the exit aperture width $d$, the entrance aperture radius $R$ and the side profile height $h_{p}$ (Figure 4). Radius $R$ of the side profile is determined by the radius of the entrance aperture which in turn is determined by its three parameters $x_{c}, y_{c}, R_{c}$ (see Equation (4) and Figure 2). Assuming a square exit aperture with $d$ $=0.01 \mathrm{~m}$ sides, the hyperbolic side profile has effectively only one parameter, namely the side profile height $h_{p}$. The entire GOCRSH parametric design has therefore a total of four parameters $x_{c}, y_{c}, R_{c}$ and $h_{p}$. 


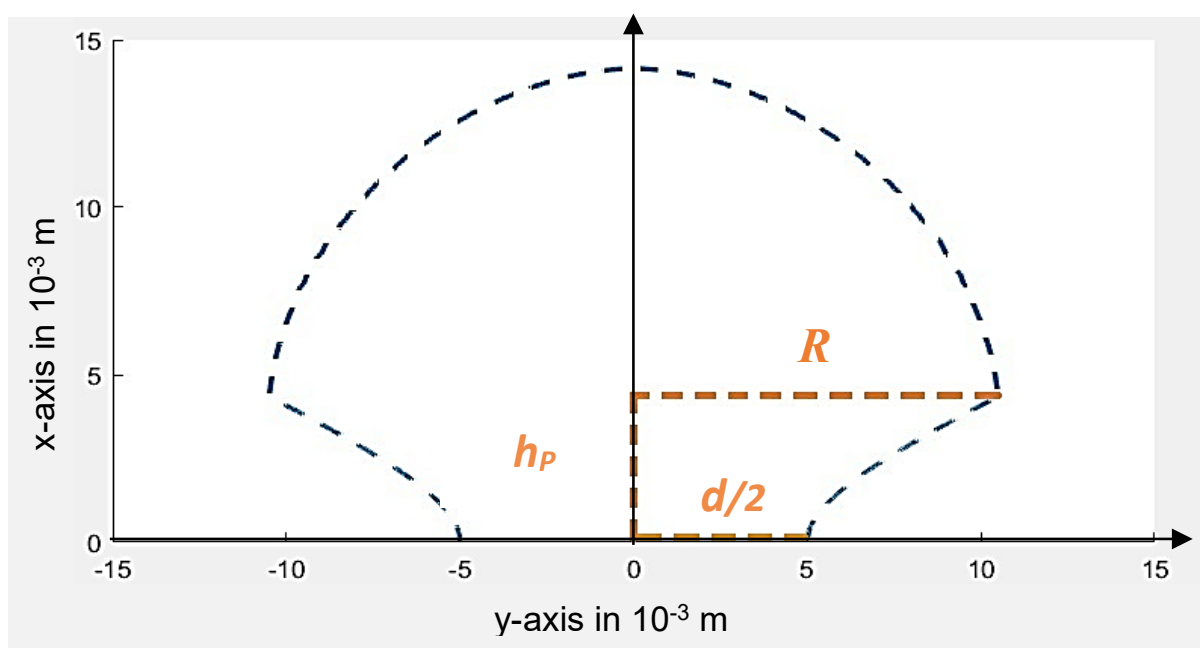

Figure 4. Parameters of the GOCRSH hyperbolic side profile

The side profile connects the circular entrance aperture to a square exit aperture, its slope therefore changes with the angle of rotation $\theta_{t h}$ as defined in Figure 5. The changing exit aperture width, renamed $a$, is defined according to Equation (6), where $\tau$ is defined according to Equation (7) [6].

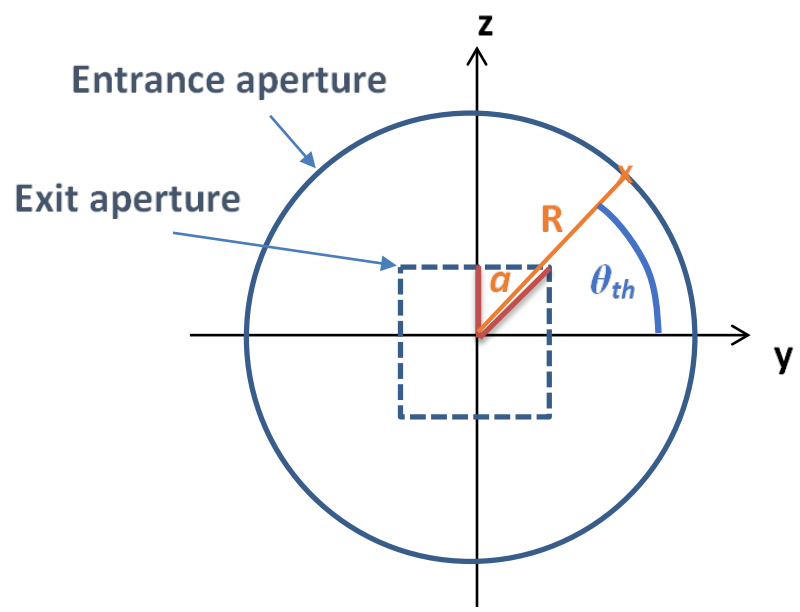

Figure 5. Change in cross-section parameters of the GOCRSH, Top view of the circular entrance aperture and square exit aperture

$$
a\left(\theta_{t h}\right)=\frac{d}{2 \times \tau\left(\theta_{t h}\right)}
$$




$$
\tau\left(\theta_{t h}\right)=\left\{\begin{aligned}
\cos \theta_{t h}, & 0<\left|\theta_{t h}\right| \leq \frac{\pi}{4} \\
\sin \theta_{t h}, & \frac{\pi}{4}<\left|\theta_{t h}\right| \leq \frac{3}{4} \pi \\
-\cos \theta_{t h}, & \frac{3}{4} \pi<\left|\theta_{t h}\right| \leq \pi
\end{aligned}\right.
$$

The points of the hyperbolic side profile were generated using the parametric equation of the hyperbola as given in Equation (8) and its parameters are illustrated in Figure 6 for $\theta_{t h}=$ $n \pi, n \in \mathbb{Z}$.

$$
\frac{y^{2}}{(a)^{2}}-\frac{x^{2}}{i^{2}}=1
$$

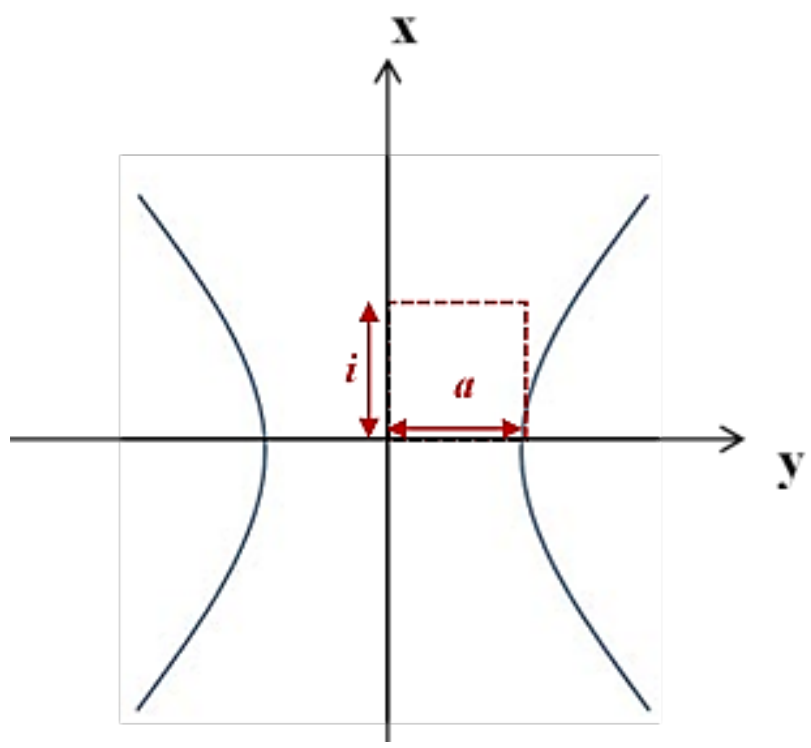

Figure 6. Parameters of the hyperbolic function used for the parametric equation of the GOCRSH side profile

To represent an arbitrary cross-section of the hyperbolic side profile of the GOCRSH, $i$ also needs to be set as a function of $a$ (Equation (9)). The 3D parametric equation of the side profile is defined in Equation (10), where $a\left(\theta_{t h}\right)$ and $i\left(\theta_{t h}\right)$ are as defined in Equations (6) and (9) respectively and $r$ as defined in Equation (5).

$$
i\left(\theta_{t h}\right)=\frac{h_{P} \times a\left(\theta_{t h}\right)}{\sqrt{R^{2}-a\left(\theta_{t h}\right)^{2}}}
$$




$$
f_{p}\left(\theta_{t h}, r\right)=\sqrt{\left(\frac{r^{2}}{a\left(\theta_{t h}\right)^{2}}-1\right) \times i\left(\theta_{t h}\right)^{2}}
$$

By changing the parameters of the side profile $R$ and $h_{P}$, the curvature of the side profile changes and therefore its property for total internal reflection (TIR). Figure 7 shows the propagation of rays for a concentrator with a constant entrance aperture curvature, entrance aperture radius and exit aperture width and with varying side profile height. It can be seen from Figure 7 that a change in parameters $R$ and $h_{p}$ has an influence on the TIR property of the side profile. Evaluating the optical concentration ratio of the design with various parameters and at various angles using raytracing, takes this property into account.

In contrast to the edge ray principle, which is commonly used for the design of nonimaging optics, this approach leads to an improved flux distribution of the solar cell, since the side profile is reduced before the ray bundle is focused onto a point (Figure 7).

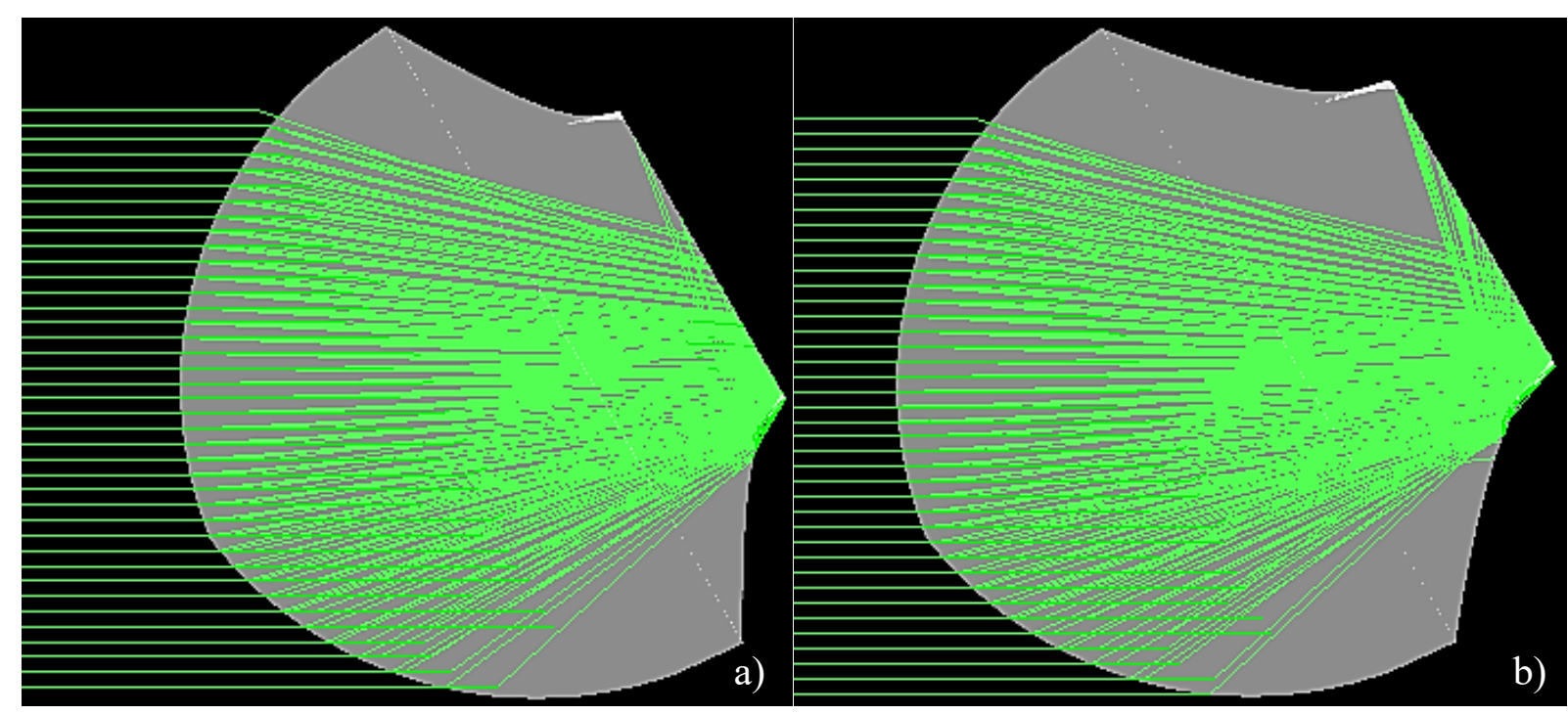

Figure 7 Change in TIR condition for $30^{\circ}$ incident rays of the GOCRSH side profile for a) a reduced side profile $b$ ) increased side profile

\section{Numerical optimisation of the GOCRSH}

\subsection{Optimisation aim}

The aim of the optimisation is to find a compact concentrator with the maximum possible

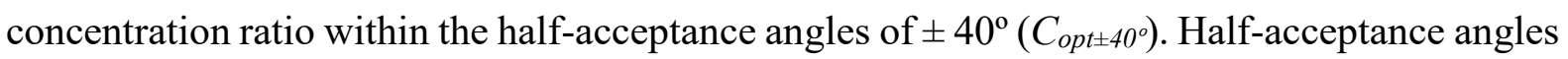


of $\pm 40^{\circ}$ allow the concentrator to collect sunrays for more than five hours given that the sun moves across the sky by $15^{\circ}$ within an hour. The aim of the optimisation is therefore to discover a set of four parameters $\left(x_{c}, y_{c}, R_{c}, h_{p}\right)$ that achieve the optimisation aim of maximum possible $C_{o p t \pm 40^{\circ}}$ at the minimum possible concentrator volume and height.

\subsection{Raytracing analysis method}

A 3D raytracing software is needed to evaluate the optical properties of the evolving designs and to feed back to the concentrator optimisation program which was decided to be written in MATLAB. To avoid interconnecting multiple software, a MATLAB integrated raytracing program Optometrika [36] was used in this work. Optometrika's library is written in MATLAB classes and is fully vectorised enabling fast raytracing analysis. Traced rays include, reflection at mirroring surfaces, total internal reflection and intensity loss at refractive surfaces. [36]. To calculate the optical efficiency, the number of ray intersections with each surface was set as output.

The parametric equations of the concentrator surfaces were integrated into Optometrika's library using a lens class for user-defined surfaces called "GeneralLens". This lens class requires parametric representation of the surface coordinates and outward normals. Further user-defined information was set as follows:

Table 2 Settings for the raytracing analysis in Optometrika

Lens material type:

Number of rays in the bundle

Diameter of the ray bundle

Rays position and direction

Pattern of rays within the bundle: hexagonal by default

linear, hexagonal, square or random

Wavelength of the ray bundle

Orientation of object
PMMA properties from material library: refractive index $=\left[\begin{array}{llll}1.491 & 1.496 & 1.488\end{array}\right]$; density $=1.185 \mathrm{~g} / \mathrm{cm}^{3}$;

1000 for GA optimisation program 10000 for detailed raytracing analysis

$0.050 \mathrm{~m}$

$\left[\begin{array}{lll}0 & 0 & 0\end{array}\right] ;\left[\begin{array}{lll}1 & 0 & 0\end{array}\right]$

Rotated when measured the angular response 
Detector size, shape and resolution $0.010 \mathrm{~m} \times 0.010 \mathrm{~m}, 256 \times 256$ bins

This concentrator analysis approach which includes the parameterisation of the surfaces and the raytracing analysis in Optometrika is validated in the following section against the common approach where the concentrator coordinates are generated in MATLAB, the 3D model in a CAD software and the raytracing carried out in ZEMAX Optic Studio. [19,37-41]. In this section the CRSH concentrator which coordinates were generated in MATLAB and imported into SolidWorks to create a 3D model is raytraced in ZEMAX (CRSH_A in [16]) and its angular response is compared to the angular response of the parameterised CRSH design raytraced in Optometrika (Figure 8). The optical concentration ratio was calculated at various angles of incidence of up to $\pm 60^{\circ}$ in increments of $5^{\circ}$. The slight differences observed in the optical concentration ratios may be due to the quality of the 3D model; Figure 9 shows the nonuniformity of the mesh, which is particularly strong in areas where the entrance aperture surface meets the side profile, and Figure 10 shows the surface roughness of the 3D model. Hence, the difference in optical concentration ratio between the angles of incidence $20^{\circ}$ to $25^{\circ}$ is larger, since the area with the uneven mesh was exposed to incoming rays at these angles.

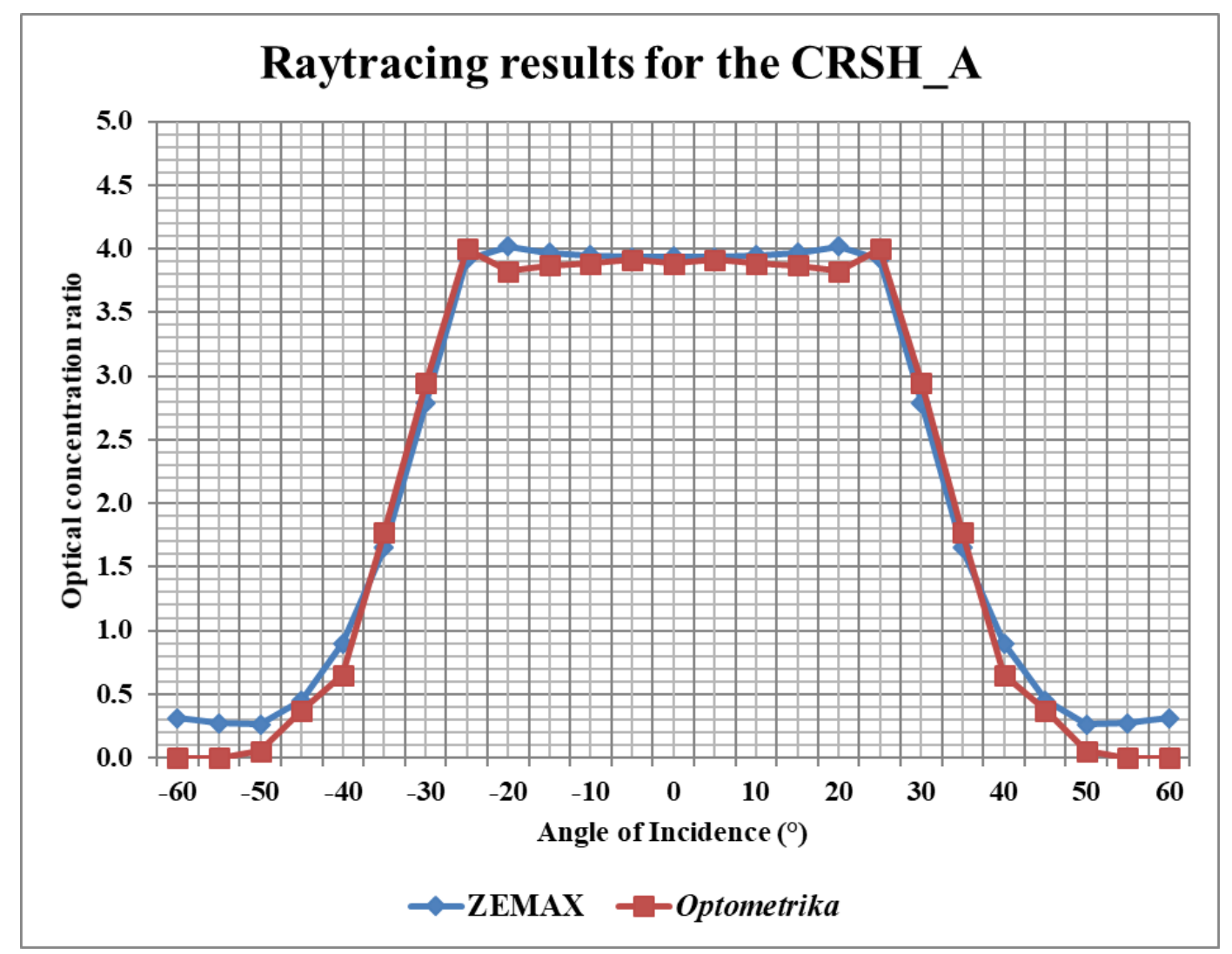

Figure 8. Comparison of the raytracing results obtained in Optometrika and ZEMAX for the CRSH 


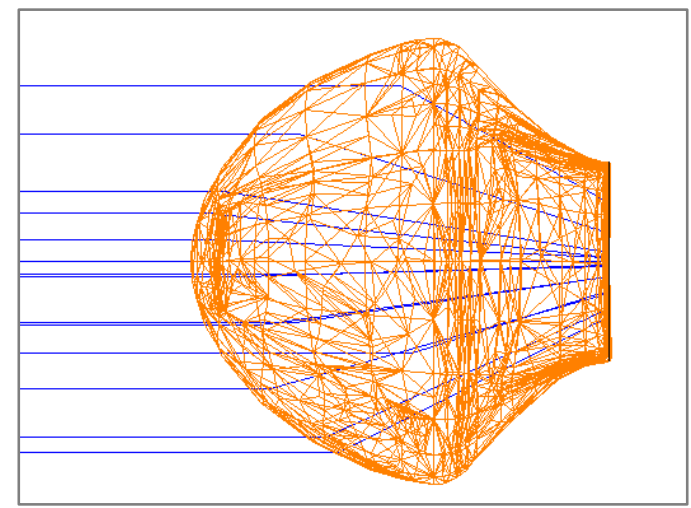

Figure 9. Mesh unevenness of the concentrator 3D model generated using the MeshPrep Wizard function in Solidworks and displayed in ZEMAX

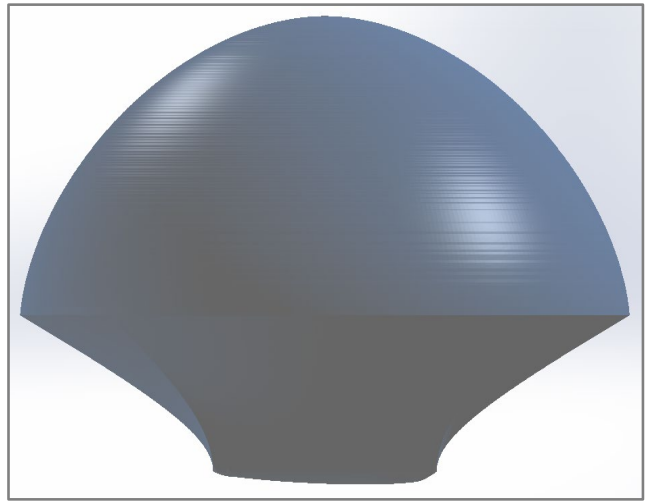

Figure 10. Surface roughness of the concentrator 3D model generated using the MeshPrep Wizard function in generated and shown in Solidworks

To calculate $C_{o p t \pm 40^{\circ}}$ during optimisation the raytracing analysis was only carried out at the angles of incidence of $0^{\circ}, 10^{\circ}, 20^{\circ}, 30^{\circ}$ and $40^{\circ}$ to reduce the computational time. The optical concentration ratios in between were linearly interpolated. The error between the calculated $C_{o p t \pm 40^{\circ}}$ by raytracing at each angle and the approximated $C_{o p t \pm 40^{\circ}}$ was only $3.2 \%$. Therefore, the approach with the reduced number of raytracing analyses was used for this optimisation.

\subsection{Optimisation parameters}

The choice of optimisation parameters such as population size, selection method, crossover rate and mutation rate are discussed in various works $[42,43]$. However, their conclusions are solely guidelines, since all parameters are problem dependant [23,24]. Experimental work carried out by M. Juric [44] shows that the optimisation parameters recommended for the type of problem he was solving [43], did not achieve satisfactory results. Therefore, combinations of parameters are tested in this paper for the optimisation of nonimaging concentrators.

\section{Boundaries}

The GA is initialised with random parameter values sampled from the search space. The boundaries are based on the parameter values we received when fitting the parametric equation of the GOCRSH to the CRSH designs described in [16]. The values are given in $10^{-3} \mathrm{~m}$ :

$$
-3<x_{c}<0, \quad-3<y_{c}<0, \quad 5<R_{e}<20 \text {, and } \quad 1<h_{p}<10 \text {. }
$$

The parameter values are encoded into binary using the MATLAB integrated function dec2bin to increase the number of possible chromosomes resulting from crossover and mutation. To 
allow for four decimal places, the parameters are multiplied by 10000 and divided by the same number before the parameters are passed on to the raytracing analysis. The maximum possible length of encoded parameters was set to 18 bits.

\section{Population size}

The first optimisation parameter to be set is the population size $N$. A population of 50 individuals was chosen according to the guidelines as described in [24]. However, the first optimisation parameter is more arbitrary with further optimisation parameters needing to be adjusted to it.

\section{Objective and fitness function}

The performance of the individuals was evaluated based on an objective function. This function describes how close the performance of the evaluated concentrator design is to the desired performance or how it compares to that of other concentrators within the population. As described in the previously published conference paper [35] the objective function was developed stepwise using experimental testing. The choice of the objective function influences the resulting concentrator volume, concentrator height and the average $C_{o p t \pm 40^{\circ}}$ of the optimised concentrator design. Whilst $C_{o p t \pm 40^{\circ}}$ is a value which is retrieved through raytracing, the volume and concentrator height are both functions of the input parameters $x_{c}, y_{c}, R_{c}$ and $h_{p}$. The aim of this optimisation is to find a design with the maximum optical concentration ratio within the angles of incidence of $\pm 40^{\circ}\left(C_{o p t \pm 40^{\circ}}\right)$ a minimum concentrator volume $(\mathrm{V})$, and a minimum concentrator height $\left(h_{m}\right)$. These three optimisation goals are combined into one objective function (Equation (11)). The constants $d_{f 1}=1 \mathrm{~m}^{-1}$ and $d_{f 1}=1 \mathrm{~m}^{-3}$ were added to be dimensionally correct.

$$
\begin{gathered}
f_{i}\left(C_{o p t_{\_} i} h_{m_{-} i} V_{i}\right)=\frac{\sum_{0 \underline{0}}^{40 \underline{0}} C_{o p t_{-} i}-d_{f 1} \times h_{m_{\_} i}}{\sqrt[k]{d_{f 2} \times V_{i}}} \\
\text { with }=[1: N]
\end{gathered}
$$

Given that the aim of the optimisation is to maximise $f_{i}$, the average optical concentration ratio $\left(C_{o p t \pm 40^{\circ}}\right)$ will be maximised while the volume $(V)$ and concentrator height $\left(h_{m}\right)$ will be minimised. Changing the root values $k$ of the volume, concentrator designs with different volumes and gains are achieved. Based on this objective function, each individual is allocated a fitness value $f_{i}$ where $i$ stands for the numbered individual within the population. 


\section{Selection}

From the fitness values of the individuals, a selection probability is calculated by dividing $f_{i}$ by the sum of all $f_{i}$ (Equation (13)). The selection probability determines the chances of the individual to be selected for mating.

$$
f_{S_{-} i}=\frac{f_{i}}{\sum_{1}^{N} f_{i}}
$$

There are different approaches to select individuals for the next generation. Rank, tournament and fitness proportional selection are the most common selection methods [43]. In rank-based selection, the individuals are ranked according to their fitness. The least fit individual is allocated position 1 whilst the fittest individual is allocated position $N$, with the other individuals being ranked between 1 and $N$. This selection method has the advantage of reducing the differences between very fit and average individuals, preventing premature convergence and thus entrapment of the algorithm in a local optima [24].

Tournament selection is the most popular selection operator in GA [45]. In tournament selection individuals are picked for mating based on their relative rank within the population. A number of individuals (tournament size) is randomly selected and the fittest of those is chosen for mating. The tournament size is typically 2 or 3 individuals; the larger the tournament size, the lower the chance of the less fit individuals to go forward and the diversity reduces faster [45].

Fitness proportional roulette wheel selection is another popular selection method where the probability of selection is proportional to the fitness of the individual[24]. Analogous to spinning a roulette wheel, the selection probabilities of the individuals are added one by one until the sum exceeds a randomly generated number between 0 and 1 [24]. The individual at which the addition / roulette wheel stops, is selected for mating. To adjust the selection algorithm to a given problem, the difference in selection probability between very fit and average individuals can be increased or decreased with an approach called fitness scaling. The fitness values of the population are pivoted about the average population fitness $f_{\text {ave }}$ and the highest fitness within the population $f_{\max }$ using a parameter $c_{m}$ (Equations (14) - (16)) [24]. 


$$
\begin{gathered}
f_{i}^{\text {scaled }}=c \times f_{i}+d \\
c=\frac{\left(c_{m}-1\right) \times f_{\text {ave }}}{f_{\text {max }}-f_{\text {ave }}} \\
d=(1-c) \times f_{\text {ave }}
\end{gathered}
$$

For $c_{m}=2$ twice as many very fit individuals as average individuals go forward [24]. The influence of the $c_{m}$ factor can be observed in Figure 11, where for $c_{m}=1$ all scaled fitness values $f_{i}^{\text {scaled }}$ are equal. To prevent negative probabilities, probabilities which would be negative due to fitness scaling are set to 0 .

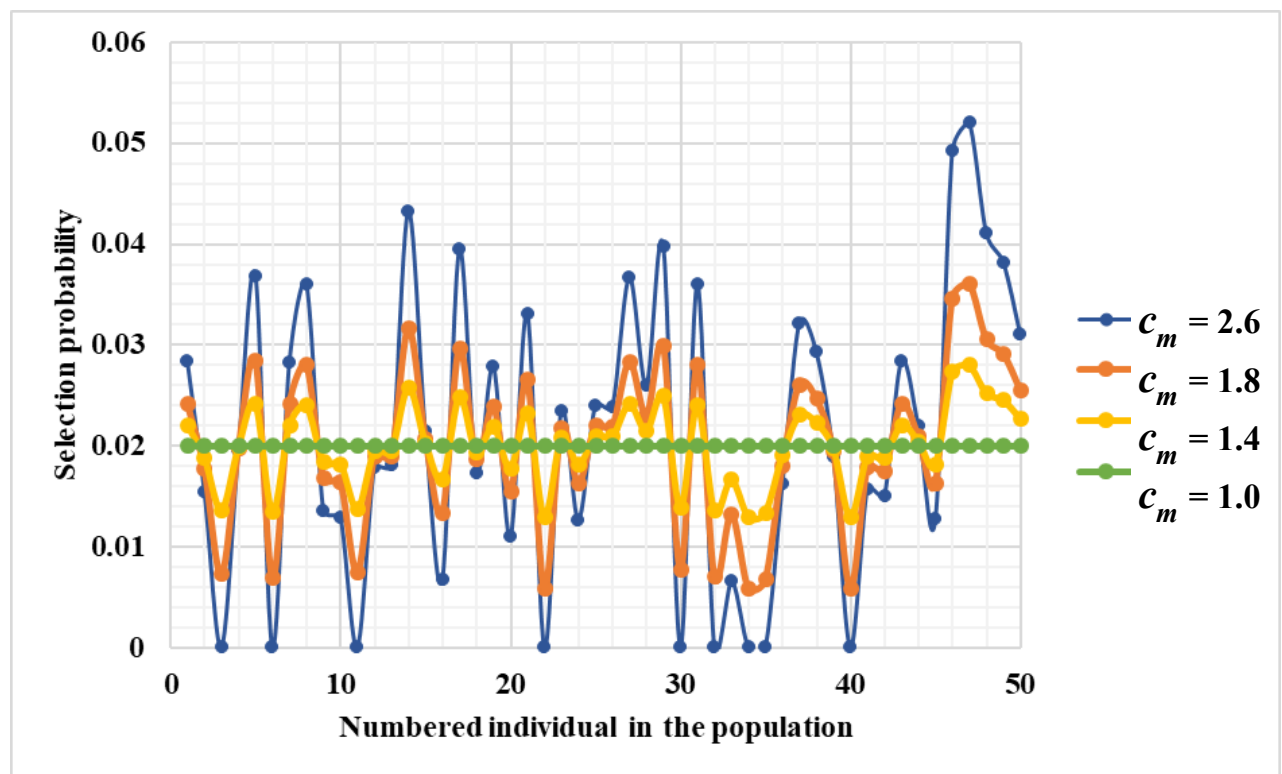

Figure 11. Scaled fitness values with varying $c_{m}$ factor for the roulette wheel selection method

The influence of $c_{m}$ on the optimisation result and on the algorithm convergence speed is shown in Figure 12 and Figure 13, respectively. A high $c_{m}$ value increases the risk of premature convergence and the achieved maximum fitness value for $c_{m}=2.6$ is below the maximum fitness value achieved with $c_{m}=1.8$ and $c_{m}=1.4$. A too small $c_{m}$ on the other hand results in a small difference between very fit and average individuals and the algorithm requires more time to explore the search space (Figure 13). Hence, a $c_{m}$ of around 1.8 is recommended for the given optimisation problem, chosen population size, boundaries and selection method. 


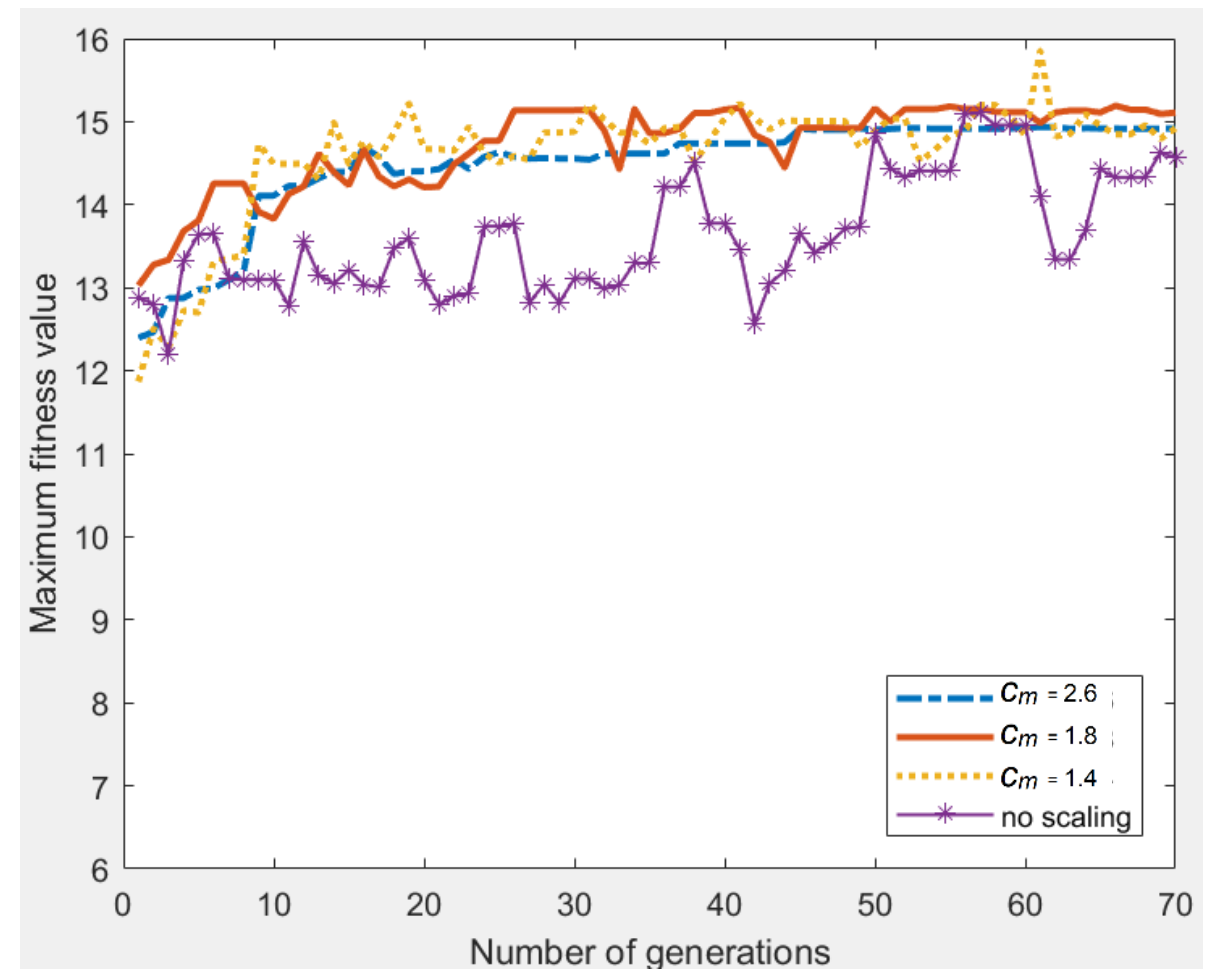

Figure 12. Influence of the fitness scaling factor $c_{m}$ on the change in the maximum fitness value over generations for the roulette wheel selection method

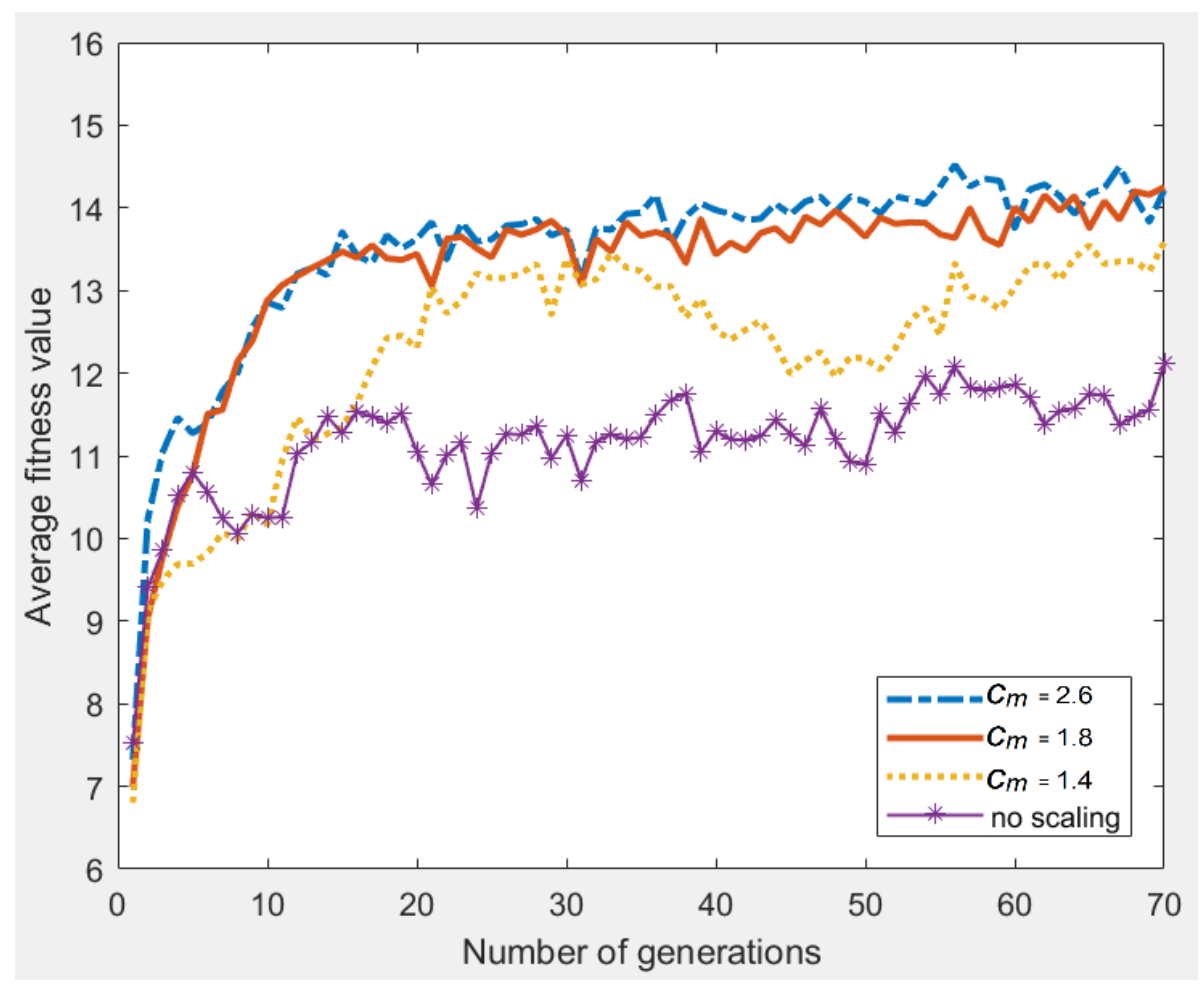

Figure 13. Influence of the fitness scaling factor $c_{m}$ on the change in the average fitness value over generations for the roulette wheel selection method 
Lastly, two popular selection methods are compared: fitness proportional roulette wheel selection with fitness scaling $\left(c_{m}=1.8\right)$ and tournament selection with a tournament size of two. Figure 14 shows that with tournament selection the algorithm conversion is steadier than the fitness proportional roulette wheel selection with fitness scaling. Based on these results and on the recommendations mentioned above, tournament selection was chosen for the studied optimisation problem. The tournament size was set to two individuals and the selection process was repeated until the population for each generation was filled.

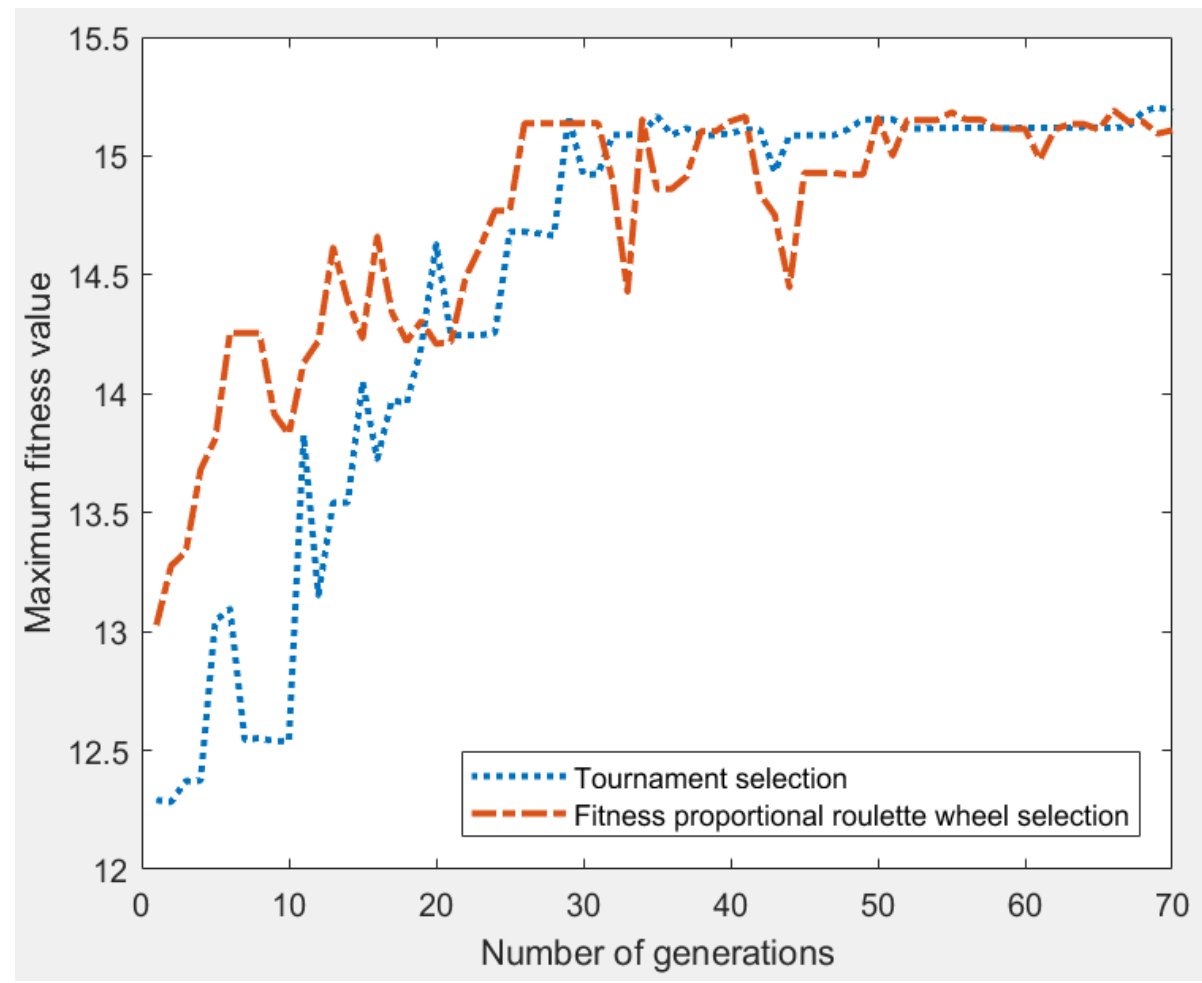

Figure 14. Algorithm convergence depicted as a change in the maximum fitness over generations with: tournament selection and proportional wheel selection with fitness scaling $\left(c_{m}=1.8\right)$

\section{Crossover}

After selection, the crossover operator was applied. To swap parts of the genetic material between two selected individuals, the encoded parameters aredivided into parts. An example of a 2-point crossover in binary form is given in Table 3. Crossover at multiple points and crossover at every gene are also possible [24]. According to a user-defined probability $P_{c}$ (typically between 0.4 and $0.9[24,43]$ ) crossover is performed on the selected concentrator pair if a randomly generated number $T_{c}$ is smaller than the user defined probability $P_{c}$, else the concentrator designs gos into the next generation unchanged. With a probability of $P_{c}=0.5$, 
half of the concentrator designs would undergo crossover. For this optimisation, 2-point crossover with a probability of $P_{c}=0.7$ was applied.

Table 3. Example of a 2-point crossover

\begin{tabular}{|c|c|c|c|c|}
\hline \multicolumn{2}{|c|}{ Parameters before crossover } & & \multicolumn{2}{|c|}{ Parameters after crossover } \\
\hline 362315 & $100|\mathbf{1 0 0} 010111001| 111$ & & $100|011111111011| 111$ & 356331 \\
\hline 196328 & $010|011111111011| 100$ & & $010|\mathbf{1 0 0} 010111001| 100$ & 202312 \\
\hline
\end{tabular}

\section{Mutation}

The mutation operator is applied after the crossover. Mutation prevents premature convergence by introducing random changes into the parameters of the concentrator designs [46,47]. According to a user defined mutation probability $P_{m}$ a binary digit of a parameter is swapped (Table 4) [24]. The algorithm steps through each binary digit of the parameters and generates a random number $T_{m}$ between 0 and 1 . If $T_{m}<P_{m}$, the bit is flipped, if not it remains unchanged. Mutation probabilities of $P_{m}=\frac{1}{L}$ and $P_{m}=\frac{1}{N * \sqrt{L}}$ are proposed in the literature, where $L$ is the number of bits of an encoded paramter (here $L=18$ ) and $N$ the number of individuals in a population (here $N=50$ ) [24]. The optimisation was run with $P_{m}=0.01$ and $P_{m}=0.02$ (Figure 15). The higher $P_{m}$ the longer the algorithm takes to converge, thus a $P_{m}$ value of 0.01 was used in this work.

Table 4 Example of mutation

\begin{tabular}{cccc}
\hline \multicolumn{2}{c}{ Parameters before mutation } & \multicolumn{2}{c}{ Parameters after mutation } \\
\hline 744 & 01011101000 & $\mathbf{7 3 6}$ & 01011100000 \\
757 & 01011110101 & $\mathbf{1 0 1 3}$ & 01111110101 \\
\hline
\end{tabular}




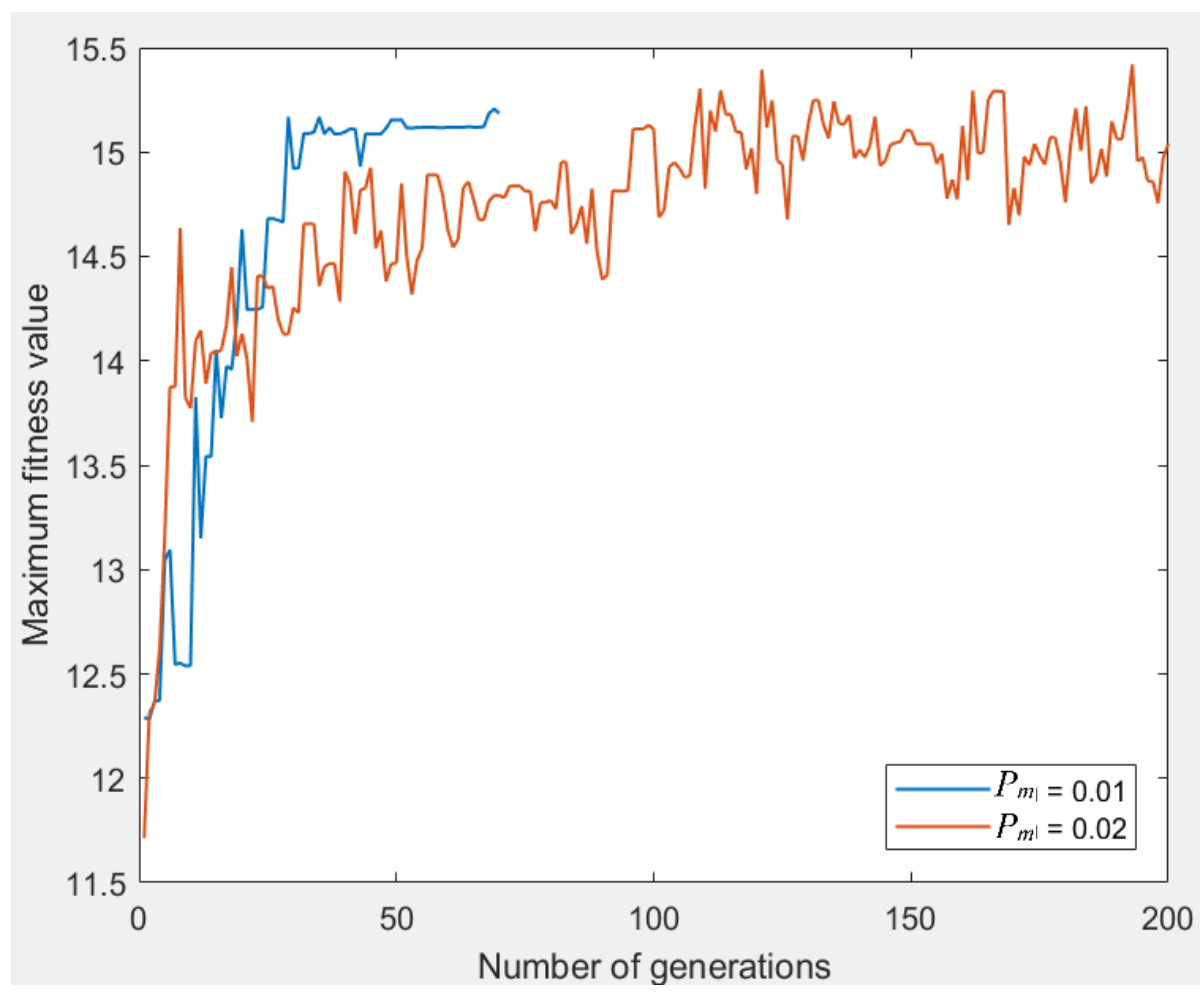

Figure 15. Change in the maximum fitness value over generations depended on the mutation rate After crossover and mutation, the new generation is set. However, crossover and mutation might have led to unfeasible parameters. If a parameter is not within the specified boundary, a random parameter within the boundaries is generated. Thus, a two narrow boundary is restrictive and interrupting to the conversion if the algorithm, while a too wide boundary leads to the examination of unfeasible individuals and a slow conversion. The optimisation algorithm stopping criteria is the maximum number of generations which is set to 70 generations according to the experimentally determined conversion speed of the algorithms. A summary of the optimisation algorithm parameters is given in Table 5.

Table 5. Overview of the selected optimisation algorithm parameters

\begin{tabular}{ll}
\hline \multicolumn{2}{c}{ Summary of optimisation algorithm parameters } \\
\hline Number of individuals in population & 50 \\
Selection method & Tournament selection, tournament size: 2 \\
Crossover method & 2-point crossover \\
Crossover probability & 0.7 \\
Mutation probability & 0.01 \\
Boundaries & yes \\
Termination criteria & 70 generations \\
\hline
\end{tabular}




\section{Results and discussion}

\subsection{Optimisation algorithm performance}

The convergence of the algorithm with algorithm parameters as summed up in Table 5, is presented in Figure 16. The maximum fitness value increases until around the $35^{\text {th }}$ generation and alternates around the highest fitness thereafter, indicating that the maximum fitness value was found. The progression of the maximum fitness can be better understood when looking at how the $C_{o p t \pm 40^{\circ}}$ of the fittest individual (Figure 17) and its volume (Figure 18) develop over generations. In the beginning when the search space is large as indicated by the "Average fitness within the population" graph in Figure 16, concentrators with volumes between 2140 and $4530 \times 10^{-9} \mathrm{~m}^{3}$ got evaluated (Figure 18). Within the first generations the search space is drastically reduced which can be seen by the jump of the $f_{\text {ave }}$ value between the $1^{\text {st }}$ and the $10^{\text {th }}$ generation. Starting off with a volume $V>4500 \times 10^{-9} \mathrm{~m}^{3}$ and a $C_{o p t \pm 40^{\circ}}<3.3 \mathrm{x}$, a much more compact designs were found towards the end of the optimisation; concentrator designs with a significantly smaller volume $<3000 \times 10^{-9} \mathrm{~m}^{3}$ and a $C_{o p t \pm 40^{\circ}}>3.5 \mathrm{x}$ were achieved. The value the algorithm settles on depends on the objective function, an objective function as shown in Equation (11) leads to a final design with a volume of around $3000 \times 10^{-9} \mathrm{~m}^{3}$.

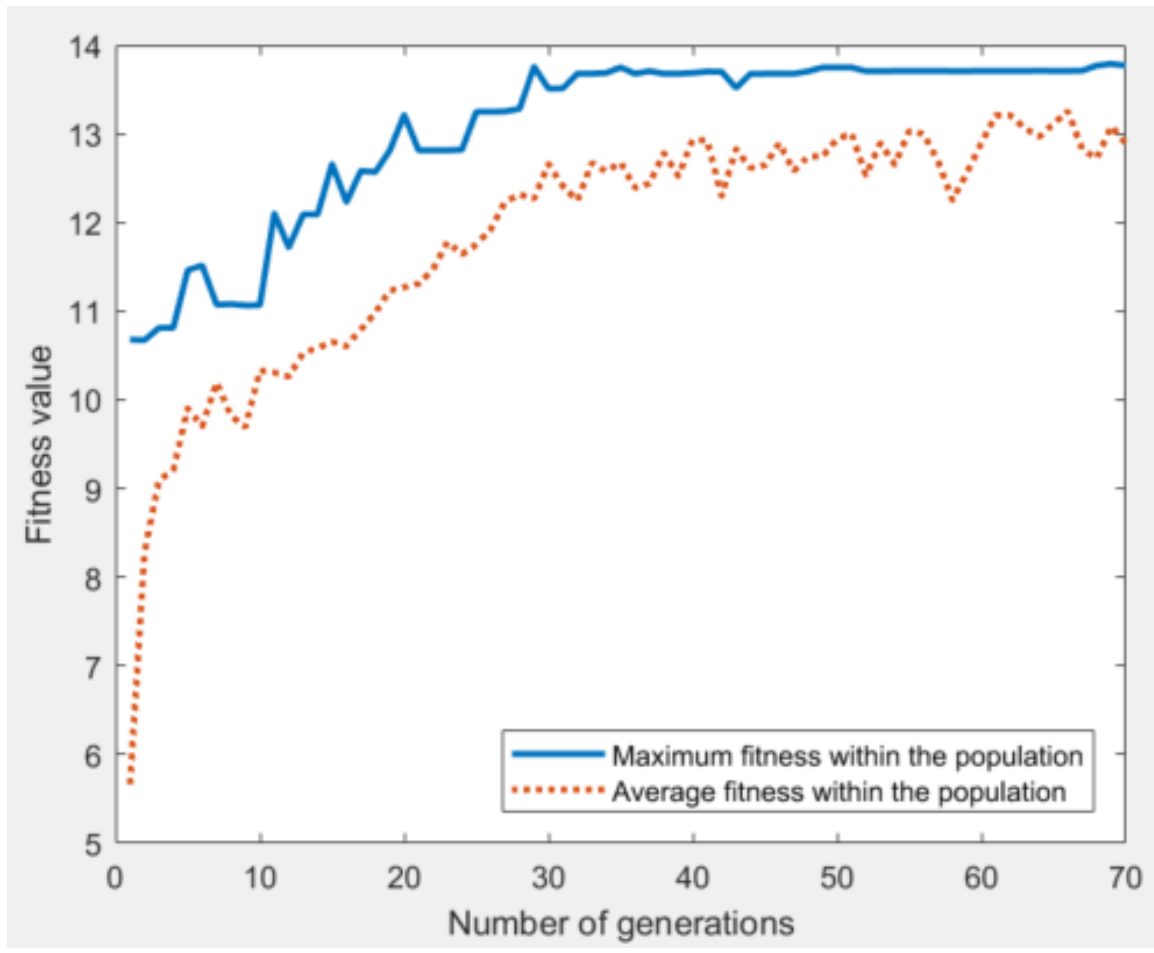

Figure 16. Algorithm performance and convergence 


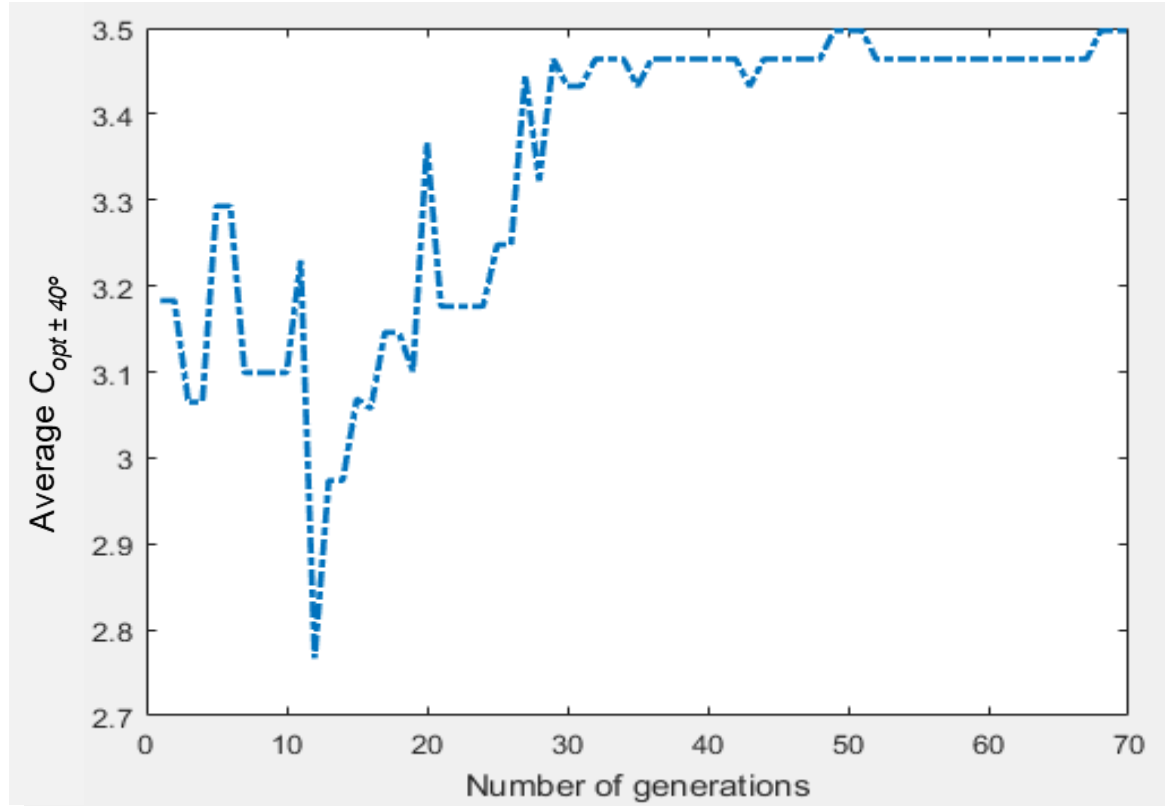

Figure 17. Change in the average optical concentration ratio $\left(C_{o p t \pm 40^{\circ}}\right)$ of the fittest individual depicted over 70 generations

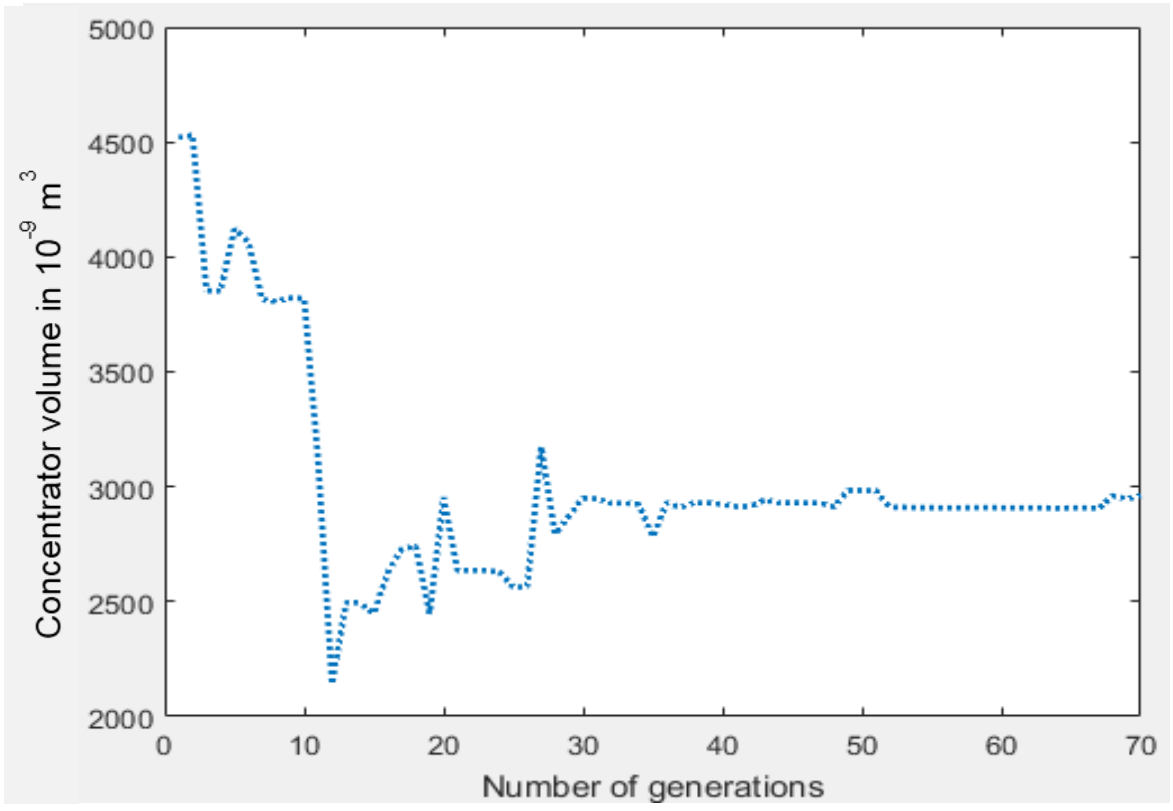

Figure 18. Change in the volume of the fittest individual depicted over 70 generations

By changing the objective function different GOCRSH concentrator designs were realised. The average optical concentration ratio $\left(C_{o p t \pm 40^{\circ}}\right)$ and the volume of 14 different designs are compared in Figure 19. The graph of average $C_{o p t}$ to concentrator volume has a gradient that reduces with larger volumes, indicating that at smaller volumes the GOCRSH designs are more compact. Since the exit aperture width is the same for all concentrators $\left(100 \times 10^{-6} \mathrm{~m}^{2}\right)$, it is 
with the bigger diameter of the concentrator entrance aperture that the design becomes less compact. This indicates that the optical losses increase with an increasing diameter and that the edge of the entrance aperture is of less optical importance. The relation between the $C_{o p t \pm 40^{\circ}}$ and the concentrator height is shown in Figure 20 indicates a proportional mathematical relationship for all optimised GOCRSH designs. This is due to the volume increasing with the power of $2 / 3$ compared to the increase in height.

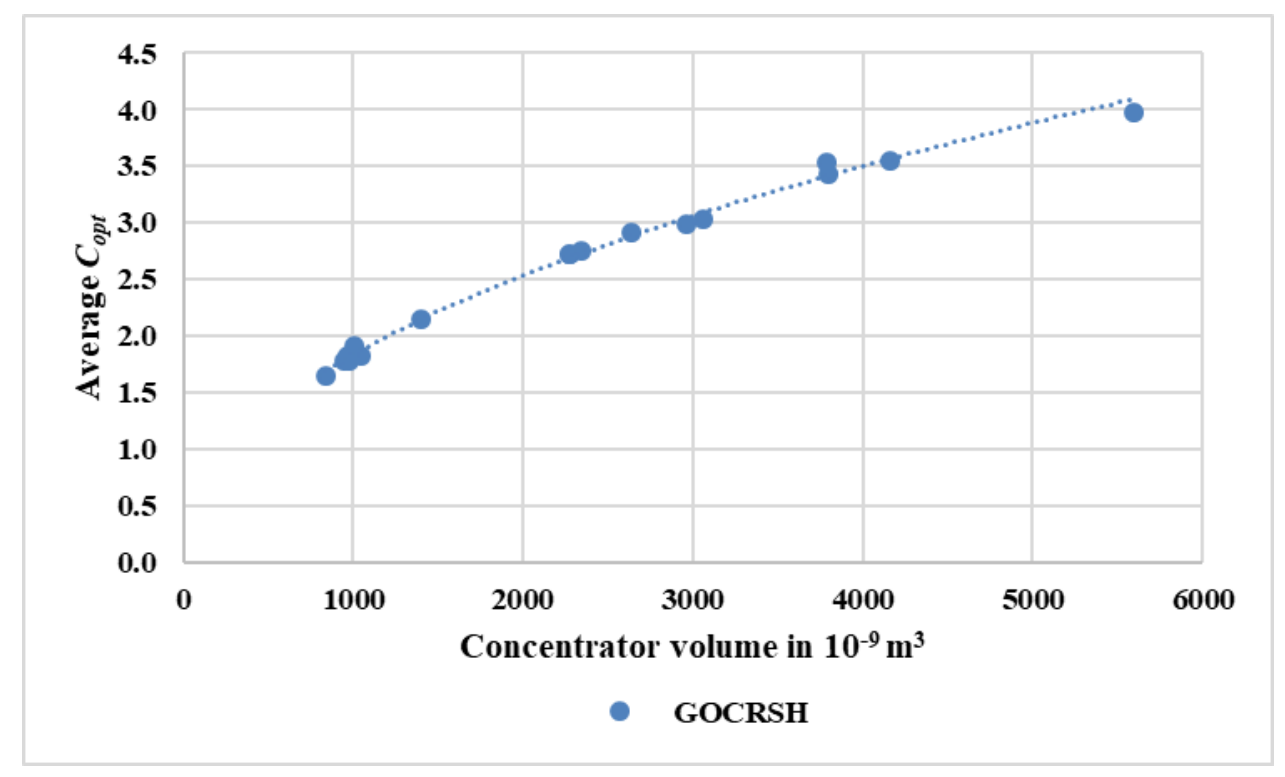

Figure 19. Relation of the average optical concentration ratio $\left(C_{o p t \pm 40^{\circ}}\right)$ to concentrator volume for 14 different GOCRSH concentrators

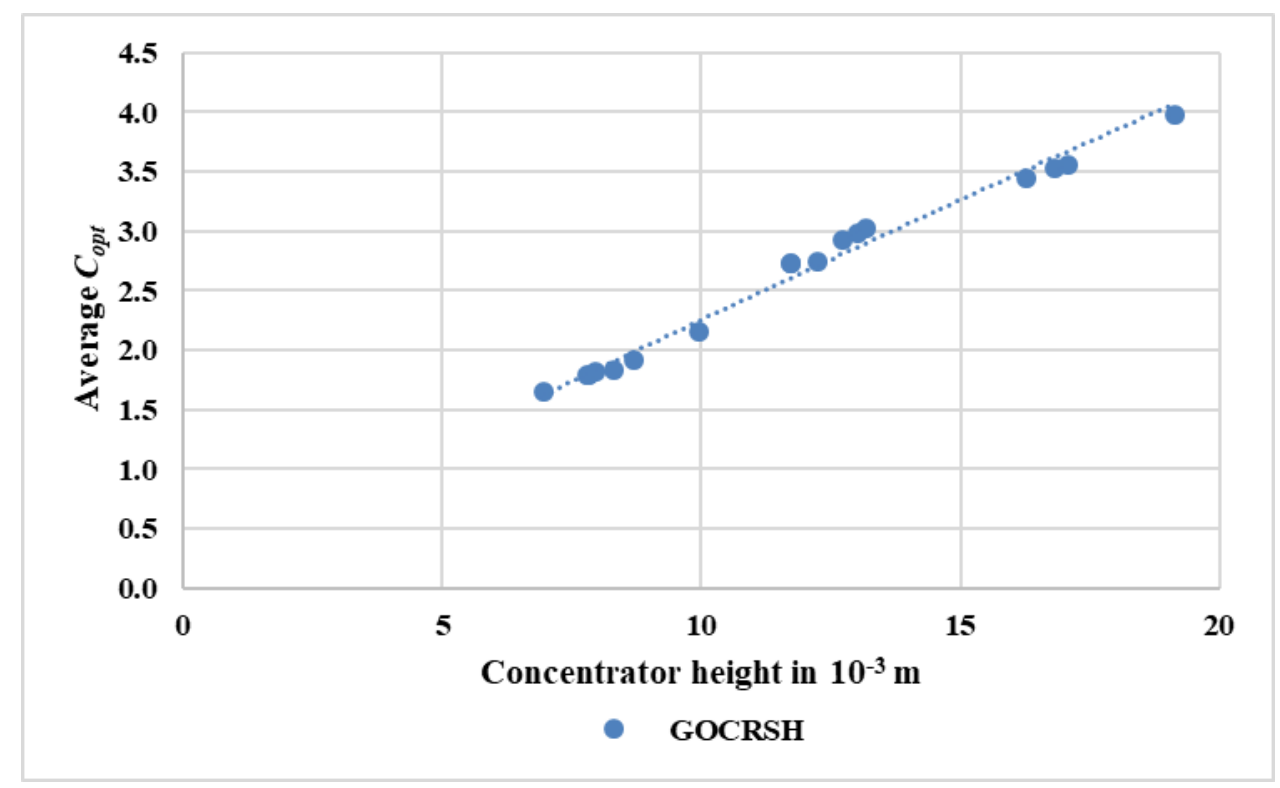

Figure 20. Relation of average optical concentration ratio $\left(C_{o p t \pm 40^{\circ}}\right)$ to concentrator height for 14 different GOCRSH concentrators 
Four GOCRSH designs with different gains and volumes were chosen for comparison with nonimaging concentrator designs previously proposed in literature. The GOCRSH designs are differentiated by the root value $k$ of the objective function they were optimised by (Equation (12)). The gain-to-volume ratio of the four optimised concentrator designs is compared in Table 6 and Figure 21 to the $\mathrm{CRSH}(\mathrm{A}, \mathrm{B}, \mathrm{C})[16]$ and to several nonimaging concentrators proposed for BICPV (RACPC [14], RADTIRC [6], 3D CCPC [13], SEH [13], Aspheric lens [15]).

Table 6. Comparison of the GOCRSH concentrators to the CRSH and to the BICPV concentrators

\begin{tabular}{lccccccc}
\hline & \multicolumn{3}{c}{ GOCRSH } & \multicolumn{3}{c}{ CRSH } \\
\hline Design & $k=2$ & $k=3$ & $k=3.6$ & $k=4$ & $\mathrm{~A}$ & $\mathrm{~B}$ & $\mathrm{C}$ \\
Volume $\left(10^{-9} \mathrm{~m}^{3}\right)$ & 1397 & 2271 & 2961 & 5594 & 7570 & 4272 & 4045 \\
Average $C_{\text {opt } \pm 40^{\circ}}$ & 2.15 & 2.73 & 2.99 & 3.97 & 3.23 & 3.27 & 3.08 \\
\hline & \multicolumn{1}{c}{ Several concentrator designs for BICPV } \\
\hline Design & RACPC & RADTIRC & 3D CCPC & SEH & Aspheric lens \\
Volume $\left(10^{-9} \mathrm{~m}^{3}\right)$ & 8538 & 8230 & 3968 & 4019 & $3200^{1}$ \\
Average $C_{\text {opt } \pm 40^{\circ}}$ & 3.41 & 3.90 & 2.64 & 1.80 & 1.88 \\
\hline
\end{tabular}

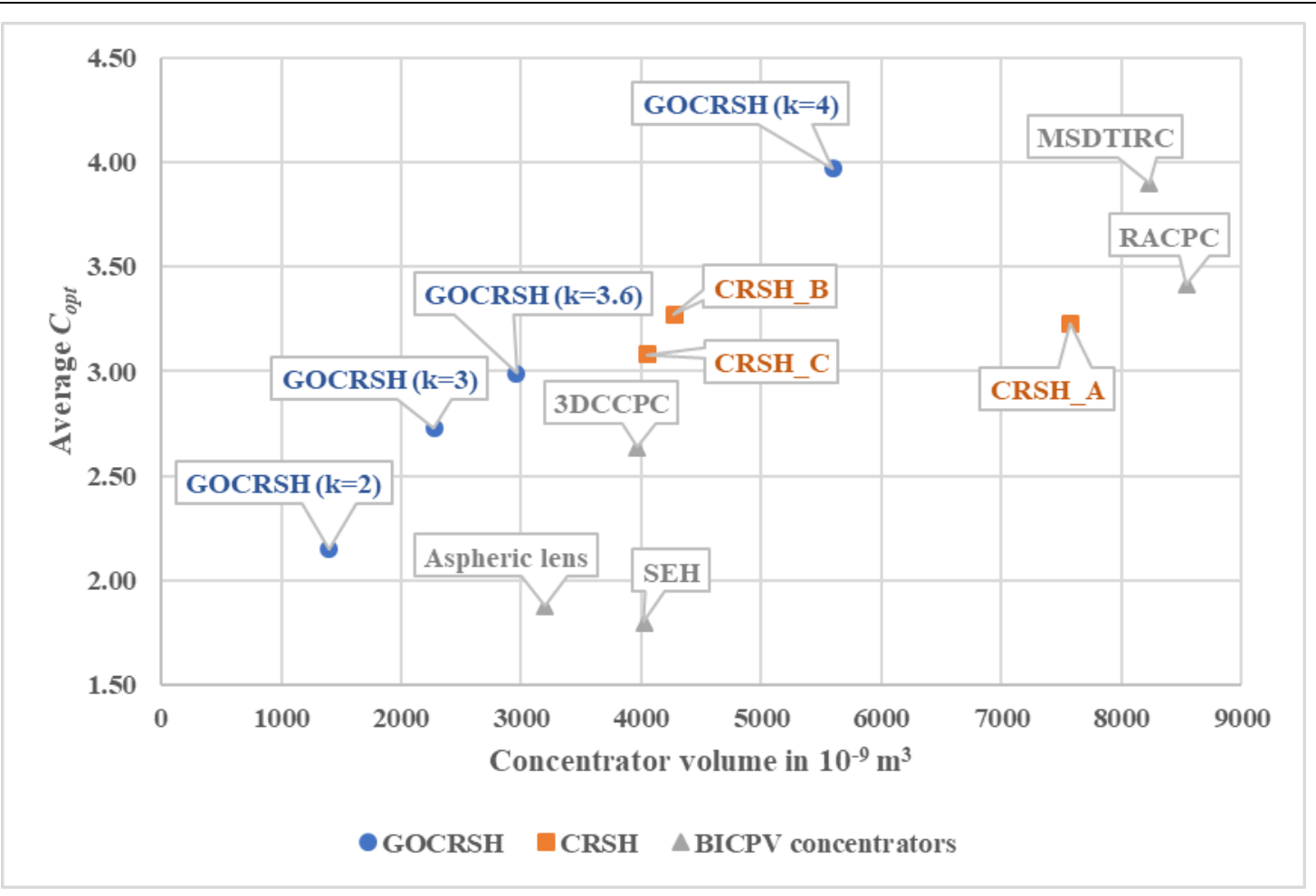

Figure 21. Comparison of the chosen GOCRSH to the CRSH and to several concentrators proposed for building integrated concentrated photovoltaics (BICPV)

\footnotetext{
${ }^{1}$ The volume of the aspheric lens is an estimated value for a $100 \mathrm{~mm}^{2}$ solar cell
} 
The GOCRSH designs are closer to the top left corner of the chart, achieving a higher gain at a smaller volume compared to the $\mathrm{CRSH}$ and compared to several concentrator designs proposed for BICPV. For instance, while CRSH_C and GOCRSH $(k=3.6)$ have a similar $C_{o p t \pm 40^{\circ}}$, the CRSH_C has a larger volume by $27 \%$. Another direct comparison can be drawn

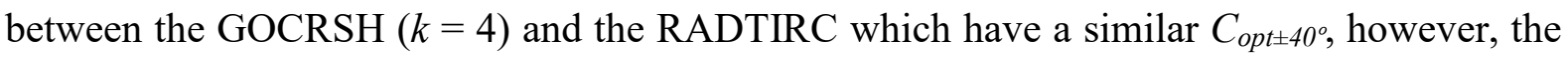
volume of the RADTIRC is larger by $32 \%$. A greater improvement can be observed between GOCRSH $(k=4)$ and the RACPC where the RACPC has a larger volume by $34 \%$ and a lower $C_{o p t \pm 40^{\circ}}$ by $16 \%$. A further comparison can be drawn between the GOCRSH $(k=3)$ and the 3D CCPC, the most compact nonimaging concentrator for BICPV. While their $C_{o p t \pm 40^{\circ}}$ are similar, the volume of the $3 \mathrm{D}$ CCPC is larger by $43 \%$ and its height by $27 \%$. As discussed in the introductory section, smaller in height and more material efficient design, not only improves the sustainability of the design but also reduces the manufacturing costs of the concentrator. Nevertheless, it has to be noted that while material efficiency is important for all applications, it was not necessary the highest priority for the BICPV designs discussed in this paper.

The aim of finding a more compact nonimaging concentrator design was achieved. To further explore the optimisation possibilities of nonimaging concentrators, first, the algorithm boundaries can be extended. Secondly, more objective functions to combine the optimisation goals can be tested. Lastly, the parametric equation of the GOCRSH is rather rigid, for more flexible optimisation B-Splines are recommended in literature [19,21]. On the other hand, a small number of parameters allows for a more effective optimisation and makes the design easier to replicate.

\section{Summary and conclusions}

To achieve the goal of universal access to affordable, sustainable and reliable electricity, the sustainability aspect of solar chargers was addressed. A static solar photovoltaic concentrator was proposed which has the potential to lower the embodied energy and greenhouse gas emissions of the solar PV module by reducing the amount of required photovoltaic material. To date little research is available on portable concentrated photovoltaic systems. The genetically optimised circular rotational hyperboloid (GOCRSH) concentrator proposed in this paper is more compact than previous nonimaging designs available in literature, it is easy to use, has an optical concentration ratio of around $3 x$ and wide half-acceptance angles of $\pm 40^{\circ}$ which enables the solar charger to capture light for more than 5 hours without tracking. The 
GOCRSH was designed by the parameterisation of a circular entrance aperture, hyperbolic side profile and square exit aperture. An optimum set of design parameters was found using the Genetic Algorithm numeric optimisation, which is a new approach in the design of static nonimaging concentrators. Various Genetic Algorithm optimisation parameters were calibrated in this paper, which can be used as guidelines for future 3D nonimaging optimisation design problems. The chosen parameters are a population size of 50 individuals, 2-point crossover with a probability of 0.7 and a mutation probability of 0.01 and an experimentally determined stopping criteria of 70 generations. The GOCRSH $(k=3)$ was shown to be a more compact design than the most compact nonimaging concentrator available in literature, the refractive 3D crossed compound parabolic concentrator (3D CCPC), showing a smaller volume by $43 \%$. This permits a smaller environmental impact and lower manufacturing costs of the concentrated portable solar system. Further research will be undertaken to analyse the flux distribution on the solar cell and the behaviour of the GOCRSH under diffuse light; simulations results will be validated the through indoor and outdoor testing.

\section{Acknowledgements}

This project was funded by Glasgow Caledonian University.

\section{References}

[1] Freier D, Ramirez-Iniguez R, Jafry T, Muhammad-Sukki F, Gamio C. A review of optical concentrators for portable solar photovoltaic systems for developing countries. Renew Sustain Energy Rev 2018;90:957-68. https://doi.org/10.1016/J.RSER.2018.03.039.

[2] Vellini M, Gambini M, Prattella V. Environmental impacts of PV technology throughout the life cycle: Importance of the end-of-life management for Si-panels and CdTe-panels. Energy 2017;138:1099-111. https://doi.org/10.1016/j.energy.2017.07.031.

[3] Silicon Valley Toxics Coalition. Toward a Just and Sustainable Solar Energy Industry $2009 . \quad \mathrm{http}$.//staging.community-wealth.org/sites/clone.communitywealth.org/files/downloads/paper-mulvaney-et-al.pdf (accessed July 5, 2018).

[4] Mulvaney D. Solar Energy Isn't Always as Green as You Think. IEEE Spectr 2014. $\mathrm{http}$ ://spectrum.ieee.org/green-tech/solar/solar-energy-isnt-always-as-green-as-youthink (accessed April 26, 2016).

[5] Lamnatou C, Baig H, Chemisana D, Mallick TK. Environmental assessment of a building-integrated linear dielectric-based concentrating photovoltaic according to 
multiple life-cycle indicators. J Clean Prod 2016;131:773-84. https://doi.org/10.1016/j.jclepro.2016.04.094.

[6] Muhammad-Sukki F, Abu-bakar SH, Ramirez-iniguez R, McMeekin SG, Stewart BG, Sarmah N, Mallik TK, Munir AB, Mohd Yasin SH, Abdul Rahim R. Mirror symmetrical dielectric totally internally reflecting concentrator for building integrated photovoltaic systems. Appl Energy 2013;113:32-40. https://doi.org/10.1016/j.apenergy.2013.07.010.

[7] Winston R, Minano JC, Benitez P. Nonimaging Optics. London: Elsevier Academic Press; 2005.

[8] Chemisana D. Building integrated concentrating photovoltaics: A review. Renew Sustain Energy Rev 2011;15:603-11. https://doi.org/10.1016/j.rser.2010.07.017.

[9] Fraas L, Minkin L, Huang JAHX, Fraas J, Uppal P. Portable concentrating solar power supplies. 35th IEEE Photovolt Spec Conf 2010:3025-9.

[10] Fraas L, Avery J, Minkin L, Huang HX, Uppal P. Portable concentrated sunlight power supply using 40\% efficient solar cells. IEEE J Photovoltaics 2011;1:236-41. https://doi.org/10.1109/JPHOTOV.2011.2172576.

[11] Barnett A, Kirkpatrick, Douglas Honsberg, Christiana Moore D, Wanlass M, Emery K, Schwartz R, Carlson D, Bowden S, Aiken D, Gray A, Kurtz S, Kazmerski L, Steiner M, Gray J, Davenport T, Schmidt G. Very high efficiency solar cell modules. Prog Photovoltaics Res Appl 2009;17:75-83. https://doi.org/10.1002/pip.852.

[12] Mojiri A, Taylor R, Thomsen E, Rosengarten G. Spectral beam splitting for efficient conversion of solar energy - A review. Renew Sustain Energy Rev 2013;28:654-63. https://doi.org/10.1016/j.rser.2013.08.026.

[13] Sellami N. Design and characterisation of a novel translucent solar concentrator, $\mathrm{PhD}$ Thesis. Heriot-Watt University, 2013.

[14] Abu-Bakar SH, Muhammad-Sukki F, Ramirez-Iniguez R, Mallick TK, Munir AB, Mohd Yasin SH, Abdul Rahim R. Rotationally asymmetrical compound parabolic concentrator for concentrating photovoltaic applications. Appl Energy 2014;136:36372. https://doi.org/10.1016/j.apenergy.2014.09.053.

[15] Ota Y, Nishioka K, Araki K, Ikeda K, Lee KH, Yamaguchi M. Optimization of static concentrator photovoltaics with aspherical lens for automobile. Conf Rec IEEE Photovolt Spec Conf 2016;2016-Novem:570-3. https://doi.org/10.1109/PVSC.2016.7749660.

[16] Freier D, Ramirez-Iniguez R, Gamio C, Jafry T, Muhammad-Sukki F. Novel nonimaging solar concentrator for portable solar systems for developing countries. 2017 IEEE PES PowerAfrica 2017:307-10. https://doi.org/10.1109/PowerAfrica.2017.7991242.

[17] BASF Corporation Engineering Plastics. Estimating cooling times in injection molding 2007. http://www2.basf.us/PLASTICSWEB/displayanyfile?id=0901a5e1801499d3 (accessed November 2, 2017). 
[18] Proto Labs. Injection moulding design guidelines: thermoplastics 2018. https://www.protolabs.co.uk/services/injection-moulding/plastic-injectionmoulding/design-guidelines/ (accessed May 1, 2018).

[19] Kudaev S, Schreiber P. Automated optimization of non-imaging optics for luminaries. Proc SPIE 2005;5962:59620B-59620B - 9. https://doi.org/10.1117/12.625379.

[20] Yamada N, Nishikawa T. Evolutionary algorithm for optimization of nonimaging Fresnel lens geometry. Opt Express 2010;18:A126-32. https://doi.org/10.1364/OE.18.00A126.

[21] Shatz NE, Bortz JC. Inverse engineering perspective on nonimaging optical design. Proc. SPIE Nonimaging Opt. Maximum Effic. Light Transf. III, vol. 2538, SPIE; 1995, p. $136-56$.

[22] Cavazzuti M. Optimization Methods: From Theory to Design. Berlin Heidelberg: Springer Verlag; 2013. https://doi.org/10.1017/CBO9781107415324.004.

[23] Gallagher K, Sambridge M. Genetic Algorithms: a Powerful Tool for Large-Scale Nonlinear Optimization Problems. Comput Geosci 1994;20:1229-36.

[24] Coley DA. An Introduction to Genetic Algorithms for Scientists and Engineers. Singapore: World Scientific; 1998.

[25] Weise T. Global Optimization Algorithms-Theory and Application. vol. 1. Second Edi. Self Published; 2009. https://doi.org/doi=10.1.1.64.8184.

[26] Cvijovic D, Klinowski J. Taboo search: an approach to the multipleminima problem for continuous functions. In: Pardalos PM, Romeijin H., editors. Handb. Glob. Optim. Volume 2, Kluwer Academic Publishers; 2002, p. 387-406.

[27] Assaf J, Shabani B. Multi-objective sizing optimisation of a solar-thermal system integrated with a solar-hydrogen combined heat and power system, using genetic algorithm. Energy Convers Manag 2018;164:518-32. https://doi.org/10.1016/J.ENCONMAN.2018.03.026.

[28] Man KF, Tang KS, Kwong S. Genetic algorithms: Concepts and applications. IEEE Trans Ind Electron 1996;43:519-34. https://doi.org/10.1109/41.538609.

[29] Smith JE. Genetic Algorithms. In: Pardalos PM, Romeijn HE, editors. Handb. Glob. Optim. Volume 2, Kluwer Academic Publishers; 2002, p. 275-362.

[30] Reid DR, Smith GS. Design and optimization of Fresnel zone plates using a Genetic algorithm and a fullelectromagnetic simulator 2009;51:2223-7. https://doi.org/10.1002/mop.

[31] Chen W, Uang C, Jou C. Optimal design of an irregular Fresnel lens for multiple light sources using a three-layered Hierarchical Genetic Algorithm 2007;15:370-9.

[32] Tien Dung ND, Wang K-J, Chuang F-S, Kung K-Y. Optimizing the design of receiver in parabolic trough by using genetic algorithm. Eur J Mech - B/Fluids 2015;49:146-52. https://doi.org/10.1016/J.EUROMECHFLU.2014.08.003. 
[33] Arias-Rosales A, Mejía-Gutiérrez R. Optimization of V-Trough photovoltaic concentrators through genetic algorithms with heuristics based on Weibull distributions. Appl Energy 2018;212:122-40. https://doi.org/10.1016/J.APENERGY.2017.11.106.

[34] Mcgookin EW. Genetic Algorithm Optimisation of a Ship Navigation System. Acta Polytech 2001;41:13-9.

[35] Freier D, Ramirez-Iniguez R, Muhammad-Sukki F, Gamio C. Design method for nonimaging solar photovoltaic concentrators using genetic algorithms. AIP Conf. Proc., vol. 2012, 2018, p. 30006. https://doi.org/10.1063/1.5053505.

[36] Yury.

Optometrika.

MathWorks

2018.

https://uk.mathworks.com/matlabcentral/fileexchange/45355-optometrika (accessed August 1, 2018).

[37] ZEMAX LLC. Getting started Using OpticStudio. 2014. https://doi.org/10.1887/0750306920/b833c1.

[38] Ali IMS. Design and Analysis of a Novel 3-D Elliptical Hyperboloid Static Solar Concentrator for Process Heat Applications Submitted by Institute of Mechanical, Process and Energy Engineering School of Engineering and Physical Sciences Edinburgh , United Kingdom 2013.

[39] Tsai C-Y. Improved irradiance distribution on high concentration solar cell using freeform concentrator. Sol Energy 2015;115:694-707. https://doi.org/10.1016/j.solener.2015.03.032.

[40] Abu-Bakar SH, Muhammad-Sukki F, Freier D, Ramirez-Iniguez R, Mallick TK, Munir AB, Mohd Yasin SH, Abubakar Mas'ud A, Md Yunus N. Performance analysis of a novel rotationally asymmetrical compound parabolic concentrator. Appl Energy 2015;154:221-31. https://doi.org/10.1016/j.apenergy.2015.04.122.

[41] Ritou A, Voarino P, Bernardis S, Hilt T, Aitmani A, Dominguez C, Baudrit M. Microconcentrator with a self-assembly process. AIP Conf Proc 2016;1766. https://doi.org/10.1063/1.4962103.

[42] Goldberg DE, Deb K. A Comparative Analysis of Selection Schemes Used in Genetic Algorithms. Found Genet Algorithms 1991;1:69-93. https://doi.org/10.1.1.101.9494.

[43] Goldberg DE. Genetic algorithms in search, optimization, and machine learning. Addison-Wesley Longman Publishing Co., Inc.; 1989.

[44] Juric M. Optimizing genetic algorithm parameters for multiple fault diagnosis applications. Proc Tenth Conf Artif Intell Appl 1994:434-40. https://doi.org/10.1109/CAIA.1994.323643.

[45] Razali NM, Geraghty J. Genetic algorithm performance with different selection strategies in solving TSP. Proc. World Congr. Eng., vol. II, London: 2011, p. 4-9.

[46] Chen YM, Lee $\mathrm{CH}, \mathrm{Wu} \mathrm{HC}$. Calculation of the optimum installation angle for fixed solar-cell panels based on the genetic algorithm and the simulated-annealing method. IEEE

Trans

Energy

Convers

2005;20:467-73. 
https://doi.org/10.1109/TEC.2004.832093.

[47] Jiang Z, Dougal RA. A novel, digitally-controlled, portable photovoltaic power source. Conf Proc - IEEE Appl Power Electron Conf Expo - APEC 2005;3:1797-802. https://doi.org/10.1109/APEC.2005.1453291. 